\title{
Non-canonical Hedgehog Signaling Pathway in Cancer: Activation of GLI Transcription Factors Beyond Smoothened
}

OPEN ACCESS

Edited by:

Kaushlendra Tripathi,

University of Alabama at Birmingham,

United States

Reviewed by:

Rada Amin,

University of Alabama at Birmingham,

United States

Ralph Buttyan,

University of British Columbia,

Canada

Jin Jiang,

UT Southwestern Medical Center,

United States

*Correspondence:

Silvia Pietrobono

silvia.pietrobono@ittumori.it

Barbara Stecca

b.stecca@ispro.toscana.it;

barbara.stecca@ittumori.it

Specialty section:

This article was submitted to Stem Cell Research,

a section of the journal

Frontiers in Genetics

Received: 11 April 2019

Accepted: 24 May 2019

Published: 12 June 2019

Citation:

Pietrobono S, Gagliardi S and

Stecca B (2019) Non-canonical

Hedgehog Signaling Pathway

in Cancer: Activation of GLI

Transcription Factors Beyond

Smoothened. Front. Genet. 10:556.

doi: 10.3389/fgene.2019.00556
Silvia Pietrobono*, Sinforosa Gagliardi and Barbara Stecca*

Tumor Cell Biology Unit - Core Research Laboratory, Institute for Cancer Research, Prevention and Clinical Network (ISPRO), Florence, Italy

The Hedgehog-GLI (HH-GLI) pathway is a highly conserved signaling that plays a critical role in controlling cell specification, cell-cell interaction and tissue patterning during embryonic development. Canonical activation of $\mathrm{HH}-\mathrm{GLI}$ signaling occurs through binding of $\mathrm{HH}$ ligands to the twelve-pass transmembrane receptor Patched 1 (PTCH1), which derepresses the seven-pass transmembrane G protein-coupled receptor Smoothened (SMO). Thus, active SMO initiates a complex intracellular cascade that leads to the activation of the three GLI transcription factors, the final effectors of the $\mathrm{HH}-\mathrm{GLI}$ pathway. Aberrant activation of this signaling has been implicated in a wide variety of tumors, such as those of the brain, skin, breast, gastrointestinal, lung, pancreas, prostate and ovary. In several of these cases, activation of HH-GLI signaling is mediated by overproduction of $\mathrm{HH}$ ligands (e.g., prostate cancer), loss-of-function mutations in $\mathrm{PTCH} 1$ or gain-of-function mutations in $\mathrm{SMO}$, which occur in the majority of basal cell carcinoma (BCC), SHH-subtype medulloblastoma and rhabdomyosarcoma. Besides the classical canonical ligand-PTCH1-SMO route, mounting evidence points toward additional, non-canonical ways of GLI activation in cancer. By non-canonical we refer to all those mechanisms of activation of the GLI transcription factors occurring independently of SMO. Often, in a given cancer type canonical and non-canonical activation of $\mathrm{HH}-\mathrm{GLI}$ signaling co-exist, and in some cancer types, more than one mechanism of non-canonical activation may occur. Tumors harboring non-canonical $\mathrm{HH}-\mathrm{GLI}$ signaling are less sensitive to SMO inhibition, posing a threat for therapeutic efficacy of these antagonists. Here we will review the most recent findings on the involvement of alternative signaling pathways in inducing GLI activity in cancer and stem cells. We will also discuss the rationale of targeting these oncogenic pathways in combination with $\mathrm{HH}$-GLI inhibitors as a promising anti-cancer therapies.

Keywords: Hedgehog, GLI, cancer, non-canonical, oncogene, tumor suppressor, targeted therapy

\section{INTRODUCTION}

Hedgehog-GLI (HH-GLI) signaling is a conserved pathway that plays critical roles during embryonic development, cellular proliferation, differentiation and stem cell maintenance (Ingham and McMahon, 2001). The mammalian apparatus of the HH-GLI pathway consists of three secreted HH ligands, Sonic Hedgehog (SHH), Indian Hedgehog ( $\mathrm{IHH}$ ) and Desert Hedgehog (DHH), 
the 12-pass transmembrane receptor Patched 1 (PTCH1), the 7-pass transmembrane G protein-coupled receptor (GPCR) Smoothened (SMO), as the obligatory signal transducer across the plasma membrane, and the three GLI transcription factors (GLI1, GLI2 and GLI3), as the executors of the transcriptional response of $\mathrm{HH}$ signaling (Varjosalo and Taipale, 2008).

Hedgehog-mediated transduction is initiated by binding of $\mathrm{HH}$ ligands to PTCH. In absence of ligand, PTCH localizes at the base of the primary cilium, an organelle that bulges from the surface of vertebrate cells acting as a signaling center specialized for $\mathrm{HH}$ signal transduction (Goetz and Anderson, 2010). Thus, the accumulation of SMO to the cilium is prevented and its activity is repressed (Denef et al., 2000; Rohatgi et al., 2007). In this condition, protein kinase A (PKA), casein kinase 1 (CK1) and glycogen synthase kinase $3 \beta$ (GSK3 $\beta$ ) phosphorylate GLI2 and GLI3, which are recognized by the F-box protein $\beta$-transducing repeat-containing protein $(\beta$-TrCP) and sequestered in the cytoplasm through the physical interaction with Suppressor of Fused (SUFU) that prevents their nucleo-cytoplasmic shuttling (Kogerman et al., 1999; Wang and Li, 2006; Pan and Wang, 2007; Niewiadomski et al., 2014). In the cytoplasm, they are subjected to proteolytic cleavage to generate $\mathrm{C}$-terminally truncated forms $\left(\mathrm{GLI}^{\mathrm{R}}\right.$ ) that repress transcription of $\mathrm{HH}$ target genes (Pan et al., 2006). In contrast to GLI2 and GLI3, GLI1 is not cleaved into a repressor form, but it is mainly regulated at transcriptional level. GLI1 protein can be also controlled by the ubiquitin-proteasome system (UPS) that recognizes two degradation signals (degrons) within the GLI1, one on the C-terminus (degron $\mathrm{D}_{C}$ ) and the other on N-terminus (degron $\mathrm{D}_{N}$ ), preventing inappropriate signaling activity (Huntzicker et al., 2006) (Figure 1A).

Activation of the HH-GLI pathway is triggered by binding of $\mathrm{HH}$ ligand that displaces PTCH1 from the primary cilium, thus inducing its internalization and lysosomal degradation (Rohatgi et al., 2007). This allows SMO to be phosphorylated and activated through its association with $\mathrm{CK} 1 \alpha$ and GPCR kinase 2 (GRK2) (Chen et al., 2011) and to translocate to the cilium likely through its association with $\beta$-arrestin (Corbit et al., 2005; Kovacs et al., 2008; Chen et al., 2011). Active SMO translates the extracellular $\mathrm{HH}$ stimulus that prevents GLI2 and GLI3 processing and promotes their dissociation from SUFU, leading to translocation of full-length and active GLI $\left(\mathrm{GLI}^{\mathrm{A}}\right)$ into the nucleus, where they activate transcription of $\mathrm{HH}$ target genes, including factors involved in cell proliferation, survival, selfrenewal and invasiveness. Among targets there is also GLI1 itself (Katoh and Katoh, 2009; Gupta et al., 2010), which represents a reliable marker for $\mathrm{HH}$ pathway activation and requires functional GLI2 and GLI3 for its transcriptional activation (Dai et al., 1999; Ikram et al., 2004) (Figure 1B).

The HH-GLI signaling pathway is required during embryonic development and tissue homeostasis. After birth HH-GLI signaling is turned off and it remains active only in specific progenitor/stem cells, where it is involved in tissue repair and regeneration. However, its abnormal reactivation during childhood or the adult life can lead to cancer. Persistent activation of HH-GLI signaling has been reported in several cancers, including solid tumors and hematological malignancies, where it has been associated with tumor development, progression and recurrence after chemotherapy via the regulation of residual cancer initiating cells (Hanna and Shevde, 2016). Deregulated $\mathrm{HH}-\mathrm{GLI}$ signaling can be the result of (i) ligand-independent activation due to inactivating mutations in PTCH1 or SUFU, activating mutations in $S M O$, or $G L I$ gene amplifications (i.e., in basal cell carcinoma (BCC), SHH-subtype medulloblastoma, rhabdomyosarcoma); (ii) autocrine/juxtacrine ligand-dependent activation, in which tumor cells increase $\mathrm{HH}$ ligand expression and respond to the same $\mathrm{HH}$ stimulation in a cell-autonomous manner (i.e., glioblastoma, melanoma, lung, breast, stomach and prostate cancers); (iii) paracrine ligand-dependent activation, where $\mathrm{HH}$ ligands secreted by tumor cells turn on $\mathrm{HH}$ signaling in the surrounding stroma, which, in turn, stimulates growth and survival of the tumor and vice versa (i.e., pancreatic and colorectal cancers) (reviewed in Barakat et al., 2010; Teglund and Toftgård, 2010; Amakye et al., 2013; Cochrane et al., 2015).

However, cumulative evidence indicates that regulation of GLI expression and activity may occur also in response to other signaling pathways besides PTCH-SMO, reducing therapeutic efficacy of SMO antagonists. In this review we will focus on additional modes of GLI activation in cancer and cancer stem cells (CSCs) that occur independently of SMO. The existence of these non-canonical mechanisms appears relevant to allow the development of novel therapeutic approaches to eradicate tumors dependent on HH-GLI signaling.

\section{THE GLI TRANSCRIPTION FACTORS}

GLI proteins are members of the Gli-Kruppel family of zincfinger (ZNF) containing transcription factors (TFs), with five $\mathrm{C}_{2} \mathrm{H}_{2}$-Kruppel type ZNF motifs constituting the specific DNA binding domain. ZNF4 and ZNF5 bind specifically to a 9 base pair DNA consensus sequence (9-mer) 5'-GACCACCCA-3' within the GLI-target gene promoters (Kinzler and Vogelstein, 1990), whereas ZNF1-3 contribute to stabilize the DNA binding domain by interacting with the phosphate backbone (Pavletich and Pabo, 1993). A nuclear export sequence (NES) and a canonical bipartite nuclear localization signal (NLS), the latter adjacent to the fifth ZNF domain, ensure the nucleo-cytoplasmic shuttling of GLI (Bauer et al., 2015) (Figure 2). Although the three GLI TFs bind the 9-mer with similar affinity, different GLI can preferentially activate target genes in a context-dependent manner. Indeed, only the two cytosine-pairs flanking the central adenine within the consensus site are critical for GLI binding, whereas the other positions can tolerate a certain degree of flexibility (Winklmayr et al., 2010). Further, epigenetic changes in the regulatory regions of GLI target genes, the presence of specific GLI co-factors or the cooperation with other transcription factors can alter the DNA binding affinity of GLI to their targets and affect the transcriptional output (Regl et al., 2004; Asaoka et al., 2010; Peterson et al., 2012).

All GLI proteins possess a SUFU-interacting site located on their N-terminus (SIN) (Han Y. et al., 2015), which is responsible for SUFU-mediated cytoplasmic retention of GLI1. GLI2 and GLI3 contain an additional SUFU-interacting site on their C-terminus (named SIC) (Han Y. et al., 2015), that 


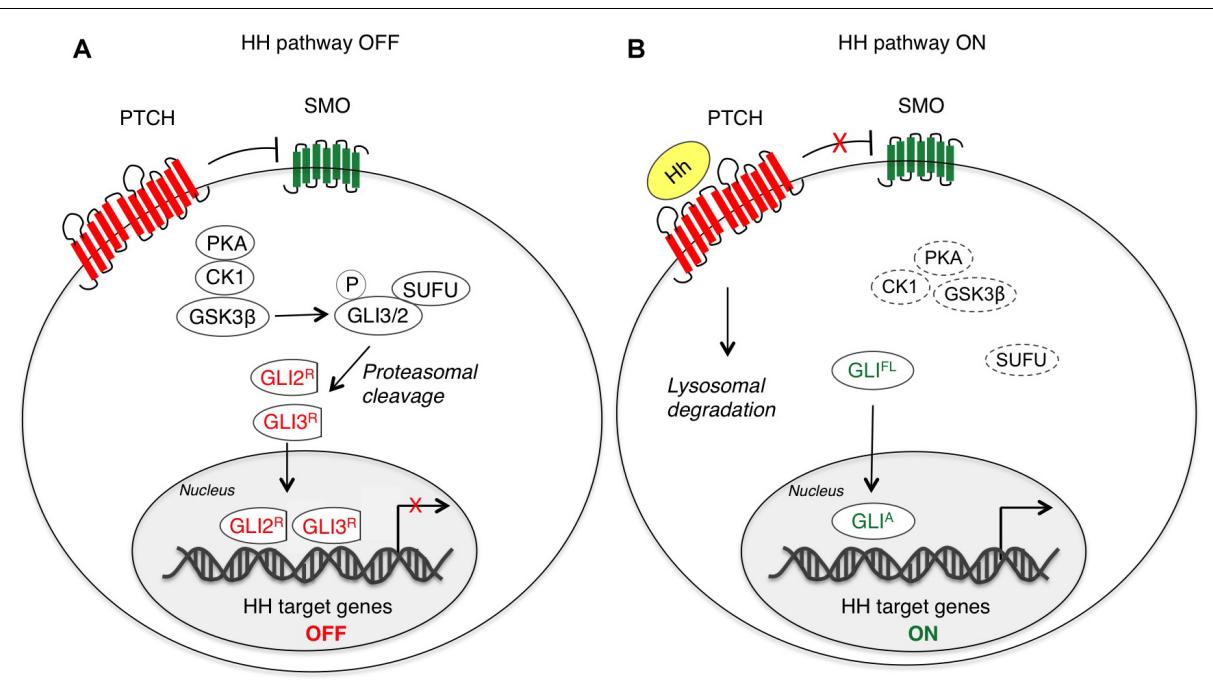

FIGURE 1 | Canonical activation of HH-GLI signaling. In absence of the HH ligand (A), PTCH inhibits SMO, and therefore GLI2 and GLI3 are phosphorylated by PKA, CK1 and GSK3 $\beta$, which create binding sites for the E3 ubiquitin ligase $\beta$-TrCP. GLI3 and GLI2 undergo partial proteasome degradation, leading to the formation of repressor forms $\left(G L I 3 / 2^{R}\right)$, that translocate into the nucleus where they inhibit the transcription of $H H$ target genes. Upon $H H$ ligand binding (B), the repression of SMO by PTCH is relieved, allowing accumulation and activation of SMO. Thus, SMO promotes a signaling cascade that ultimately leads to translocation of full length $(F L)$ activated forms of $\left.G L I(G L /)^{A}\right)$ into the nucleus, where they induce transcription of HH target genes. CK1, caseine kinase 1; GLI2/3R GLI2/3 repressors; GLI ${ }^{A}$, GLI activators; GLIFL, GLI full length; GSK3 $\beta$, glycogen synthase kinase 3 $\beta$; Hh, Hedgehog; PKA, protein kinase A; PTCH, Patched; SMO, Smoothened; SUFU, Suppressor of Fused.

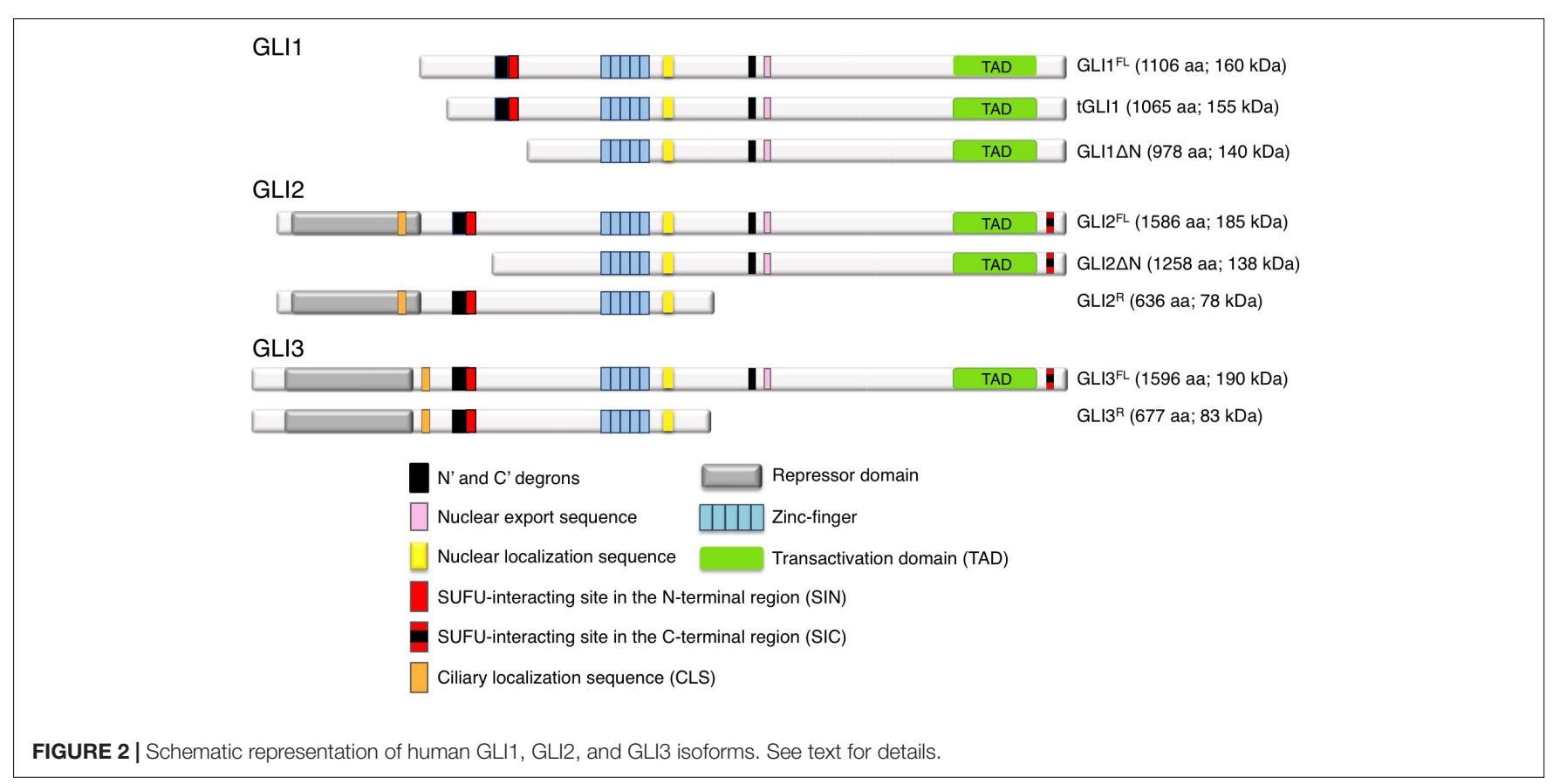

appears to be required for the inhibition of GLI transcriptional activity in the nucleus. All GLI proteins also possess a C-terminal transactivation domain (TAD), but GLI2 and GLI3 have also a N-terminal repressor domain that allows them to function as both transcriptional activators and repressors depending on cellular context, although GLI3 has been reported as a strong repressor in most settings (Tsanev et al., 2009). Thus GLI1 acts mainly as transcriptional activator (Carpenter and Lo, 2012), whereas full-length GLI2 is generally a weak activator, since the fully activated form requires the complete removal of its N-terminus (Roessler et al., 2005; Speek et al., 2006; Grachtchouk et al., 2011; Pantazi et al., 2014). A second conserved NLS containing a ciliary localization signal (CLS) has been recently identified within the N-terminal region of GLI2 and GLI3. This site has been suggested to be involved in $\mathrm{GLI}^{\mathrm{A}}$ formation without altering their proteolytic processing into $\mathrm{GLI}^{\mathrm{R}}$ (Han et al., 2017). 
Abnormal activation of GLI ${ }^{\mathrm{A}}$ and GLI1 represents a critical parameter for both tumor initiation and progression (Tojo et al., 2003; Carpenter and Lo, 2012; Iwasaki et al., 2013; Sadam et al., 2016).

The human GLI1 gene was first identified by Vogelstein and colleagues as a putative oncogene amplified in glioblastoma (Kinzler et al., 1987), and its overexpression has been reported in several tumors, including those of breast, colon, lung, ovarian, pancreas and prostate, in BCC, medulloblastoma, glioblastoma, meningioma and melanoma, where it regulates genes involved in proliferation, angiogenesis, epithelial-to-mesenchymal transition (EMT), invasiveness, CSC renewal and drug resistance (Kasper et al., 2006; Teglund and Toftgård, 2010; Aberger et al., 2012; Palle et al., 2015; Mastrangelo and Milani, 2018). In the last decade, two isoforms of GLI1, namely GLI1 $\Delta \mathrm{N}$ and tGLI1, have been described (Figure 2). The N-terminal deletion variant (GLI1 $\Delta \mathrm{N})$ is a product of alternative splicing between exon 1 and exon 4 . This event generates a protein with a 128-amino acid deletion on its N-terminus. This deletion prevents both SUFU binding and the degradation signal of GLI1 degron $\mathrm{D}_{N}$, while preserving the ZNF domains, NLS and NES, and the transactivation domain. Despite loss of SUFU-binding domain, GLI1 $\triangle \mathrm{N}$ is a labile activator and acts on target genes similarly to full-length GLI1 $\left(\mathrm{GLI1}^{\mathrm{FL}}\right)$. Further, it does not show a preferential expression in cancer tissues (Shimokawa et al., 2008). Conversely, the truncated GLI1 (tGLI1) originates from a splicing of exon 3 and part of exon 4 of the GLI1 gene, resulting in the deletion of 41 amino acids (Lo et al., 2009). This isoform retains all the functional domains present in GLI1 ${ }^{\mathrm{FL}}$ and translocates into the nucleus to activate gene transcription. However, contrarily to GLI1 ${ }^{\mathrm{FL}}$ and GLI1 $\Delta \mathrm{N}$, tGLI1 shows a tumor-specific expression, and appears to regulate an additional set of target genes involved in EMT, invasion and metastasis (Lo et al., 2009; Cao et al., 2012). Similar to $\mathrm{GLI} 1^{\mathrm{FL}}$, both these alternative spliced proteins (GLI1 $\Delta \mathrm{N}$ and tGLI1) respond to $\mathrm{HH}$ ligand stimulation, but whether and how they interact with the other components of the pathway has not yet been determined.

\section{NON-CANONICAL ACTIVATION OF GLI TRANSCRIPTION FACTORS IN CANCER AND STEM CELLS}

In addition to the canonical activation of GLI by the HH-PTCHSMO route, which is typical of normal cells and ciliated tumors, growing evidence points to a SMO-independent stimulation of GLI activity in cancer. These non-canonical mechanisms are involved both in transcriptional activation of GLI genes and in post-translational modifications of GLI proteins (summarized in Table 1), representing a heterogeneous mosaic of alterations that contribute to the development of several types of cancer with elevated GLI activity (Brechbiel et al., 2014) (Figure 3).

\section{RAS-RAF-MEK-ERK Signaling}

The RAS-RAF-MEK-ERK pathway plays pivotal roles in several cellular processes, such as cell proliferation and growth. Its constitutive activation is caused by mutations or altered stimulation of pathway components (mainly RAS, RAF, MEK) and leads to the hyperactivation of the mitogen-activated protein kinase (MAPK) extracellular signal-regulated kinase 1 and $2($ ERK1/2), which promote tumor cell growth (Samatar and Poulikakos, 2014). Several reports have described a crosstalk between the HH-GLI and RAS-RAF-MEK-ERK signaling pathways (e.g., Rovida and Stecca, 2015).

The first hint of a positive regulation of $\mathrm{HH}$ pathway by the RAS-RAF-MEK-ERK signaling came from a study showing that constitutively active MEK1 increases GLI1 activity, which is totally abrogated by inhibition of MEK1/2. Authors identified a region containing the first 130 amino acids of GLI1 responsible for sensing the status of ERK1/2 signaling. Indeed, its deletion yields to an active GLI1 protein showing decreased response to MEK1 signaling (Riobò et al., 2006a). A subsequent computational analysis identified a putative MAPK consensus site in the N-terminal region of GLI (Whisenant et al., 2010). However, evidence that ERK1/2 directly phosphorylates GLI1 is missing, suggesting the potential involvement of an additional kinase downstream of ERK1/2.

A number of reports have shown that the RAS-RAF-MEKERK signaling can modulate the $\mathrm{HH}$ pathway in several types of cancer. In human melanoma cells, oncogenic NRAS (NRAS ${ }^{Q 61 K}$ ) and HRAS (HRAS ${ }^{V 12 G}$ ) are able to enhance transcriptional activity and nuclear localization of GLI1. The cytoplasmic retention of GLI1 by SUFU is prevented by both oncogenes. Since inhibition of MEK1/2 abolishes the effect of oncogenic RAS on GLI1, it is likely that the MEK1/2-ERK1/2 module acts as the main effector of RAS (Stecca et al., 2007).

The HH-GLI pathway is important for the initiation and progression of pancreatic adenocarcinoma (PDAC), which is also characterized by high incidence of activating KRAS mutations (70-90\% of cases) (Morton et al., 2007). KRAS can activate HHGLI signaling in PDAC. Indeed, in the immortalized human PDAC cell line HPDE-c7, oncogenic KRas ${ }^{V 12}$ increases GLI1 transcriptional activity and protein levels. KRAS-mediated GLI1 activation is insensitive to cyclopamine inhibition, suggesting that is independent of SMO. GLI1 protein stability and $\mathrm{HH}$ pathway activation are decreased by pharmacological inhibition of MEK1/2 with UO126 (Ji et al., 2007). Interaction between KRAS and $\mathrm{HH}$ signaling has also been described in mouse models of PDAC. Oncogenic KRAS (KRAS ${ }^{G 12 D}$ ) cooperates with a dominant active form of Gli2 that lacks the $\mathrm{N}$-terminal repressive domain to initiate PDAC tumorigenesis in vivo (Pasca di Magliano et al., 2006). Another mouse model of KRAS-induced PDAC shows that SMO-independent activation of GLI1 is required for survival of mouse and human PDAC cells and KRAS-mediated transformation in vitro (Nolan-Stevaux et al., 2009).

In gastric cancer, KRAS positively modulates tumor proliferation increasing GLI1 transcriptional activity and expression of $\mathrm{HH}$ target genes. EGF-induced stimulation of GLI is insensitive to SMO inhibition and is blocked by MEK1 inhibition (Seto et al., 2009). Similarly, the RAS-RAF pathway induces GLI1 and GLI2 transcriptional activity and increases mRNA and protein levels in a non-canonical manner in colon cancer cells. Pharmacological and genetic 
TABLE 1 | Mechanisms of non-canonical activation of Hedgehog-GLI signaling.

\begin{tabular}{|c|c|c|c|}
\hline Upstream Regulator & Mechanism of action & Cancer/Cell type & References \\
\hline \multirow[t]{9}{*}{ MEK1/2-ERK1/2 } & $\begin{array}{l}\text { Increases expression of Gli target genes; Gli1 required for } \\
\text { KRAS-driven transformation }\end{array}$ & $\begin{array}{l}\text { KRAS-driven PDAC } \\
\text { mouse model }\end{array}$ & Nolan-Stevaux et al., 2009 \\
\hline & Increases GLI1/2 transcriptional activity & NIH3T3 & Riobò et al., 2006a \\
\hline & & Melanoma & Stecca et al., 2007 \\
\hline & & PDAC & Ji et al., 2007 \\
\hline & & Colon cancer & Mazumdar et al., 2011 \\
\hline & & LAC & Po et al., 2017 \\
\hline & Increases GLI1 nuclear localization & Melanoma & Stecca et al., 2007 \\
\hline & Induces GLI1 protein stability & PDAC & Ji et al., 2007 \\
\hline & Induces GLI2 protein stability & $\mathrm{BCC}$ & Kasper et al., 2006 \\
\hline MEK1/2-RSK2 & Promotes GLI2 nuclear localization and stabilization & Multiple myeloma & Liu et al., 2014 \\
\hline \multicolumn{4}{|l|}{ PI3K/AKT/mTOR } \\
\hline \multirow[t]{4}{*}{ AKT } & Increases Gli2 transcriptional activity & NIH3T3 & Riobò et al., 2006b \\
\hline & Increases GLI1 transcriptional activity and nuclear translocation & Melanoma & Stecca et al., 2007 \\
\hline & Enhances GLI1 protein stability & PDAC, ovarian cancer & Singh et al., 2017 \\
\hline & Prevents GLI degradation (GSK3 $\beta$-dep.) & ALCL & Singh et al., 2009 \\
\hline mTOR/S6K1 & Enhances GLI1 activation preventing SUFU association & EAC & Wang et al., 2012 \\
\hline \multirow[t]{2}{*}{ p70s6K2 } & Prevents GLI1 degradation (GSK3 $\beta$-dep.) & NSCLC & Mizuarai et al., 2009 \\
\hline & & EAC & Kebenko et al., 2015 \\
\hline \multirow[t]{2}{*}{ TGF $\beta$} & Increases GLI2 transcription (SMAD3-dep.) & PDAC, BC & Dennler et al., 2007, 2009 \\
\hline & Increases GLI2 expression & Colon CSC & Tang et al., 2018 \\
\hline \multicolumn{4}{|l|}{ DYRK family } \\
\hline \multirow[t]{2}{*}{ DYRK1A } & Promotes GLI1 nuclear translocation & NIH3T3, HEK-293T & $\begin{array}{l}\text { Mao et al., 2002; Shimokawa et al., } \\
\text { 2008; Ehe et al., } 2017\end{array}$ \\
\hline & Induces GLI1 degradation, mediated by F-actin and MKL1 & $\begin{array}{l}\text { Lung carcinoma, } \\
\text { rhabdomyosarcoma }\end{array}$ & Schneider et al., 2015 \\
\hline DYRK1B & Enhances GLI1 transcriptional activity & PDAC, MB & Gruber et al., 2016 \\
\hline DYRK2 & Induces GLI2 protein degradation & $\mathrm{NIH3T3}$ & Varjosalo et al., 2008 \\
\hline \multicolumn{4}{|l|}{ Oncogenic drivers } \\
\hline EWS/FLI1 & Induces GLI1 transcription & Ewing sarcoma & $\begin{array}{l}\text { Zwerner et al., 2008; } \\
\text { Beauchamp et al., } 2009\end{array}$ \\
\hline sox9 & Prevents $\beta$ TrCP-mediated GLI1 degradation & Pancreatic CSC & Deng et al., 2015 \\
\hline FOXC1 & Enhances GLI2 transcriptional activity & Basal-like BC & Han B.C. et al., 2015 \\
\hline c-MYC & Enhances GLI1 transcription & Burkitt lymphoma & Yoon et al., 2013 \\
\hline $\mathrm{IKK} \beta$ & Promotes GLI1 stability & DLBCL & Agarwal et al., 2016 \\
\hline SRF-MKL1 & Induces GLI transcription and enhances DNA binding & $\mathrm{BCC}$ & Whitson et al., 2018 \\
\hline WIP1 & $\begin{array}{l}\text { Enhances GLI1 transcriptional activity, nuclear localization and } \\
\text { protein stability }\end{array}$ & Melanoma & Pandolfi et al., 2013 \\
\hline
\end{tabular}


TABLE 1 | Continued

\begin{tabular}{|c|c|c|c|}
\hline Upstream Regulator & Mechanism of action & Cancer/Cell type & References \\
\hline \multicolumn{4}{|l|}{ Tumor suppressors } \\
\hline \multirow[t]{3}{*}{ p53 } & $\begin{array}{l}\text { Inhibits GLI1 transcriptional activity, nuclear translocation and } \\
\text { protein stability }\end{array}$ & Glioblastoma & Stecca and Ruiz i Altaba, 2009 \\
\hline & $\begin{array}{l}\text { Promotes proteasome-dependent degradation of GLI1 } \\
\text { (PCAF-dep.) }\end{array}$ & $\mathrm{MB}$ & Mazzà et al., 2013 \\
\hline & Interferes with DNA binding ability of GLI1 (TAF9-dep.) & $\begin{array}{l}\text { Rhabdomyosarcoma, } \\
\text { Osteosarcoma }\end{array}$ & Yoon et al., 2015 \\
\hline NUMB & $\begin{array}{l}\text { Induces GLI1 ubiquitination and proteasome degradation } \\
\text { (ITCH-dep.) }\end{array}$ & $\mathrm{MB}$ & Di Marcotullio et al., 2006, 2011 \\
\hline SNF5 & Interferes with promoter occupancy of GLI1 & Rhabdoid Tumors & Jagani et al., 2010 \\
\hline \multicolumn{4}{|l|}{ miRNAs } \\
\hline miR-324-5p & Represses GLI1 expression & CGCPS & Ferretti et al., 2008 \\
\hline \multirow[t]{2}{*}{$\operatorname{miR}-361$} & Represses GLI1 expression & Prostate cancer & Chen et al., 2017 \\
\hline & Represses GLI1 and GLI3 expression & $\begin{array}{l}\text { Retinoblastoma and } \\
\text { CSC }\end{array}$ & Zhao and Cui, 2019 \\
\hline $\operatorname{miR}-326$ & Represses GLI2 expression & Ptch+/-MB CSC & Miele et al., 2017 \\
\hline \multicolumn{4}{|l|}{ BET proteins } \\
\hline \multirow[t]{2}{*}{ BRD4 } & Increases GLI1/2 transcription & $\mathrm{BCC}$ & Tang et al., 2014 \\
\hline & & $\mathrm{MB}$ & Long et al., 2014 \\
\hline BET & Upregulates Gli1 in murine CAFs & PDAC & Yamamoto et al., 2016 \\
\hline BET & Promotes GLI occupancy on target promoters & PDAC & Huang et al., 2016 \\
\hline \multicolumn{4}{|l|}{ HDAC } \\
\hline HDAC & Stimulates GLI1 nuclear localization and transcriptional activity & Multiple Myeloma & Geng et al., 2018 \\
\hline HDAC class I & Increases DNA binding ability of GLI1 (HDAC1) & $\mathrm{MB} M B$, murine $\mathrm{BCC}$ & $\begin{array}{l}\text { Canettieri et al., } 2010 \text { Gruber et al., } \\
2018\end{array}$ \\
\hline HDAC class II & Transcriptional control of GLI2 (HDAC6) & $\mathrm{MB}$ & Dhanyamraju et al., 2015 \\
\hline \multicolumn{4}{|l|}{ HAT } \\
\hline p300 & Prevents GLI2 recruitment to chromatin & HEK-293T, NIH3T3 & Coni et al., 2013 \\
\hline \multirow[t]{2}{*}{ PCAF } & Acts as GLI1 transcriptional cofactor & Glioblastoma, MB & Malatesta et al., 2013 \\
\hline & Promotes GLI1 ubiquitination and proteolysis & $\mathrm{MB}$ & Mazzà et al., 2013 \\
\hline \multicolumn{4}{|l|}{ PRMTs } \\
\hline PRMT1 & Enhances DNA binding ability of GLI1 & PDAC & Wang et al., 2016 \\
\hline \multirow[t]{2}{*}{ PRMT5 } & Enhances GLI1 protein stabilization and nuclear translocation & $\begin{array}{l}\text { C3H10T1/2, } \\
\text { HEK-293T, SCLC }\end{array}$ & Abe et al., 2019 \\
\hline & Inhibits GLI1 expression through Menin1 & Neuroendocrine tumors & Gurung et al., 2013 \\
\hline
\end{tabular}

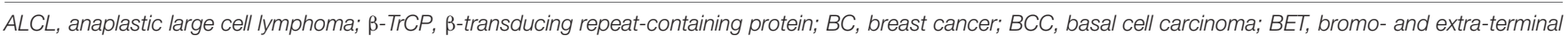

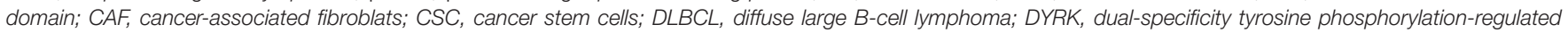
kinase; EAC, esophageal adenocarcinoma; CGCPS, cerebellar granule cell precursors; GSK3B, glycogen synthase kinase 3B; HAT, histone acetyltransferase; HDAC, histone deacetylase; LAC, lung adenocarcinoma; MEF, mouse embryonic fibroblasts; NSCLC, non-small cell lung cancer; PCAF, p300/CREB-binding proteinassociated factor; PDAC, pancreatic ductal adenocarcinoma; PKC, protein kinase C; PRMT, protein arginine methyltransferases; SCLC, small cell lung cancer; SUFU, Suppressor of Fused.

inhibition of GLI function is more effective in reducing tumor proliferation and inducing apoptosis than the inhibition of the canonical pathway at SMO level, suggesting that GLI activity is crucial for RAS/MEK-induced colon cancer proliferation (Mazumdar et al., 2011).

In lung adenocarcinoma (LAC) cells and in their CSC compartment, GLI1 is active despite SMO is often epigenetically silenced. Consistently, genetic silencing or pharmacological inhibition of GLI1, but not of SMO, reduces LAC tumor growth and stemness in vitro and in vivo ( $\mathrm{Po}$ et al., 2017). Mechanistically, GLI1 is phosphorylated and activated in a SMO-independent manner by MAPK-ERK1/2 signaling, that can be induced by KRAS or through stimulation of Neuropilin 2 receptor by its ligand VEGFA, secreted by cancer cells in an autocrine loop or by stromal cells in a paracrine manner. The cross-talk between epithelial and stromal cells appears to be mediated by the expression and secretion of SHH by LAC epithelial cells, which activates canonical HH-GLI signaling in stroma, increasing transcription of VEGFA and other GLI1 target genes (Po et al., 2017).

In multiple myelomas, the MEK1/RSK (ribosomal S6 kinase) cascade sustains non-canonical $\mathrm{HH}$ pathway activation through the stabilization of GLI2. RSK2 promotes GLI2 nuclear localization and impairs its degradation through inhibitory phosphorylation of GSK3 $\beta$ on Ser9 (Liu et al., 2014). In these cells, abnormal HH-GLI signaling correlates with the high activity of MEK/RSK signaling compared to normal B cells. Combined treatment with the RSK inhibitor SL0101 and the GLI 


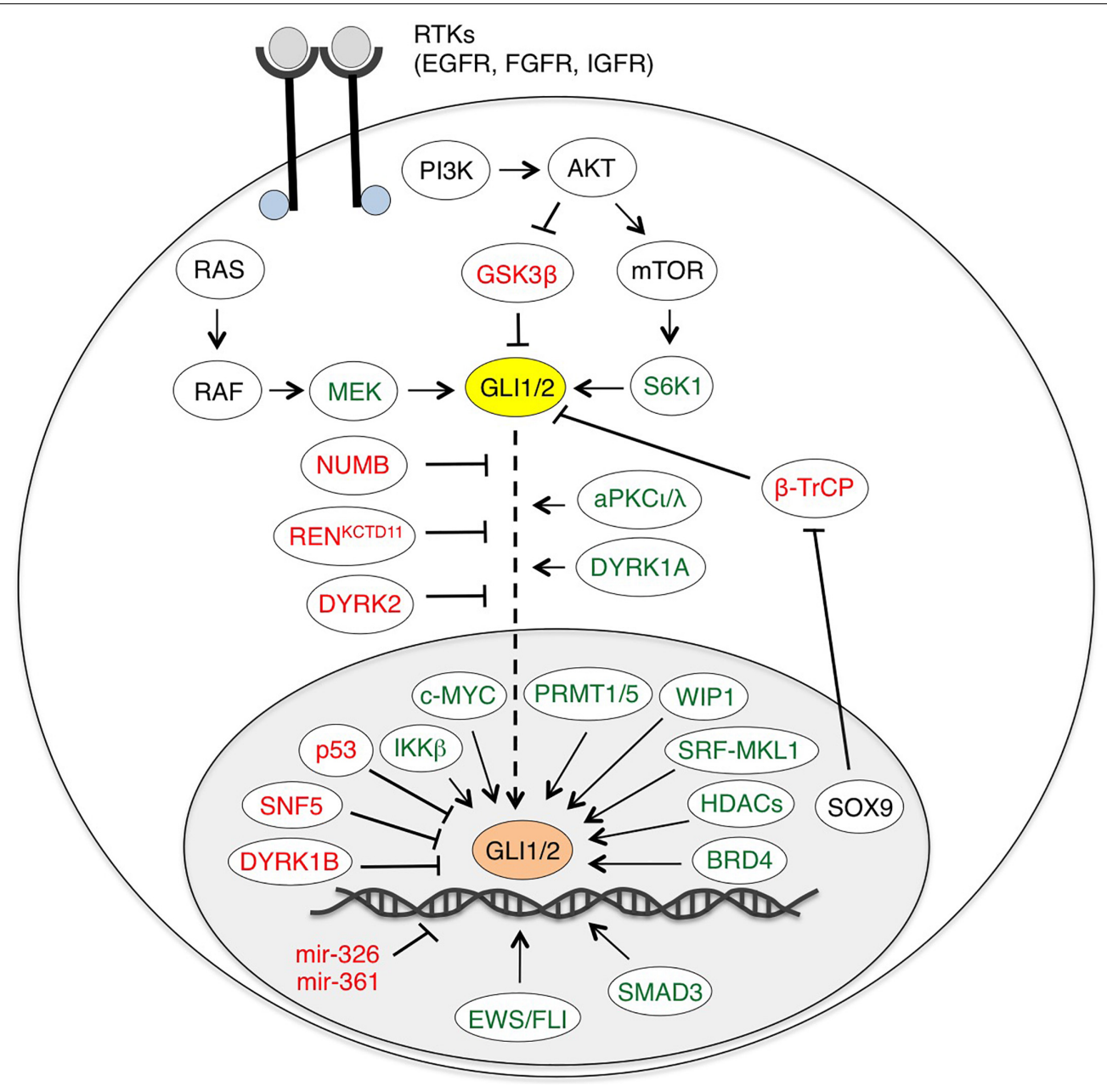

FIGURE 3 | Non-canonical activation of HH-GLI signaling by oncogenic pathways. Schematic diagram of GLI1/2 and their positive (green) and negative regulators (red). EWS/FLI, SMAD3, miR-326 and miR-361 are only direct transcriptional regulators of GLI1/2. BRD4, HDACs and SRF-MKL1 regulate both GLI1/2 expression and transcriptional activity. See text for details. Abbreviations: AKT, protein kinase $B ;$ aPKCl $/ \lambda$, atypical protein kinase $\mathrm{Cl} / \lambda$; BRD4, bromodomain-containing protein 4; $\beta$-TrCP, $\beta$-transducin repeat-containing protein; DYRK1/2, dual specificity tyrosine-phosphorylation-regulated kinase 1/2; EWS/FLI, Ewing Sarcoma/Friend Leukemia Integration 1; GSK3 $\beta$, glycogen synthase kinase 3 $\beta$; HDAC, histone deacetylase; IKK $\beta$, inhibitor of nuclear factor kappa-B kinase subunit $\beta$; MEK, MAPK (Mitogen-activated protein kinase)/ERK (extracellular signal-regulated kinase) kinase; PI3K, phosphoinositide 3-kinase; PRMT1/5, protein arginine methyltransferases 1/5; SRF-MKL1, serum response factor-megakaryoblastic leukemia 1; S6K1, ribosomal protein S6 kinase 1; WIP1, wild-type p53-induced phosphatase 1.

inhibitor GANT58 reduces myeloma cell survival and HH-GLI pathway activation with a synergistic effect (Liu et al., 2014).

Various upstream growth factor receptor tyrosine kinases (RTK) can have an impact on GLI activity independent of SMO, through the activation of the RAS-RAF-MEK1/2-ERK1/2 signaling. In human normal keratinocytes, co-expression of EGF and GLI factors enhances the activation of the HH-GLI pathway and promotes oncogenic transformation activating the MEK1/2ERK1/2 pathway (Schnidar et al., 2009). Integration of these two signaling pathways converges in the regulation of $\mathrm{HH} / \mathrm{EGFR}$ response genes, such as SOX2, SOX9, JUN, CXCR4, and FGF19, which are cooperatively induced in response to $\mathrm{HH}$ and EGFR signaling activation in BCC and in tumor-initiating pancreatic cells (Eberl et al., 2012). EGFR signaling modulates GLI target genes expression by regulating GLI1 and GLI2 interaction with their transcriptional cofactors at the promoter of their target genes (Kasper et al., 2006). MEK1/2-ERK1/2 activity upon EGFR stimulation is crucial to integrate $\mathrm{HH} / \mathrm{EGFR}$ signaling. Indeed, ERK1/2 activates the JUN/AP-1 genes, which cooperate with GLI proteins to activate downstream target genes responsible for BCC cell transformation. Moreover, activation of ERK1/2 by EGF leads to the stabilization of GLI factors, especially GLI2, preventing its proteasomal degradation (Kasper et al., 2006). Genetic and pharmacological inhibition of EGFR and MEK signaling confirms this mechanism also in medulloblastoma (Götschel et al., 2013) and in prostate cancer (Zhu et al., 2013).

Surprisingly, recent studies reported that the apical members of the MAPK cascade, the mitogen activated kinases MEKK1 and MEKK2/3, exert a negative action on GLI1. Indeed, MEKK1 overexpression strongly decreases transcriptional activity of GLI1, causing the inhibition of HH-GLI signaling and reduction of cell growth and viability of medulloblastoma cells. MEKK1 
directly phosphorylates multiple residues in the GLI1 C-terminal region, promoting the association with the 14-3-3 cytoplasmic protein and reducing GLI1 transcriptional activity (Antonucci et al., 2019). The reason of the opposite regulation of GLI1 by MEKK1 and its downstream target MEK1/2 is not clear, and further studies are required to address this issue, which is crucial to devise an effective targeted therapy. To date, only one study reports that the MEKK1/MEK1/ERK1 cascade positively regulates GLI1 in human lung fibroblasts (Cheng et al., 2016). In medulloblastoma cells MEKK $2 / 3$ mediates the negative modulation of FGF on $\mathrm{HH}$ pathway, by interacting with GLI1 and suppressing $\mathrm{HH}$-dependent medulloblastoma cell growth. MEKK2 and MEKK3 bind and phosphorylate GLI1 on multiple Serine/Threonine residues (Ser201, Ser204, Ser243, Ser968, Thr1074, Ser1078), reducing GLI1 protein stability, DNA-binding and promoting its association with SUFU (Lu et al., 2018).

\section{PI3K-AKT-mTOR Signaling}

The PI3K-AKT-mTOR signaling contributes to a variety of cellular processes, such as nutrient uptake, proliferation and survival in both physiological and pathological conditions, including cancer ( $\mathrm{Yu}$ and Cui, 2016). The first evidence of the involvement of PI3K signaling in non-canonical GLI activation came in 2006, when Riobò et al. (2006b) demonstrated that Akt prevents proteasomal degradation of Gli2 by antagonizing the inhibitory effect of PKA, thus facilitating Gli2 activation and nuclear translocation. Activation of PI3K-AKT signaling has been found to enhance GLI1 protein stability in pancreatic and ovarian cancer (Singh et al., 2017) and in anaplastic large cell lymphoma (ALCL), where AKT1 counteracts the inhibitory effect of GSK3 $\beta$ on GLI1 (Singh et al., 2009). In addition, AKT stimulates GLI1 transcriptional activity and nuclear translocation in human melanoma, prostate cancer and glioma cells, contributing to disease progression (Stecca et al., 2007). Consistently, genetic silencing of AKT or pharmacological inhibition of PI3K-AKT signaling downregulates GLI1 in human esophageal adenocarcinoma (EAC) cells (Kebenko et al., 2015). Furthermore, the PI3K-AKT-NFKB axis has been shown to mediate the activation of GLI2 in stromal cells by the cytokine CCL5. In turn, GLI2 induces transcriptional activation of IL6, which binds the IL-6R on malignant B cells, leading to immunoglobulin hyperproduction (Elsawa et al., 2011).

PI3K signaling has been also reported to increase GLI1 activity via members of the ribosomal S6 kinase family (S6K/p70-S6K), which are the downstream effectors of the PI3K-AKT-mTOR axis. For instance, in EAC cells, mTOR activation by $\mathrm{TNF} \alpha$ is responsible for S6K1 phosphorylation and activation. Activated S6K1 directly phosphorylates GLI1 at Serine residue at position 84, thus preventing its association with SUFU (Wang et al., 2012). Another member of the S6K family, p70-S6K2, has been shown to inhibit GSK3 $\beta$ through an inhibitory phosphorylation at residue Ser9, thus preventing GSK3 $\beta$-mediated GLI1 degradation (Mizuarai et al., 2009). However, the role of PI3K-AKT-mTOR in regulating GLI1 in cancer appears to be context dependent. Indeed, studies in neuroblastoma showed that S6K1 fails to modulate GLI1 activity (Diao et al., 2014), and, surprisingly,
GLI1 acts as tumor suppressor in this context and its tumorsuppressive functions are inhibited by AKT2 (Paul et al., 2013).

Smoothened-independent and PI3K-dependent noncanonical GLI activation has been related to increased in vitro proliferation and clonogenicity, and in vivo tumor growth in squamous cell lung tumors (Kasiri et al., 2017), renal cell carcinoma (Zhou et al., 2016) and colon cancer (Cai et al., 2015). The finding that heterozygous ablation of PTEN in a mouse model of medulloblastoma carrying a SmoA1 transgene promotes medulloblastoma formation (Castellino et al., 2010), strongly supports the importance of PI3K signaling as therapeutic target. In line with these data, administration of the dual PI3K/mTOR inhibitor NPV-BEZ-235 has been shown to suppress GLI1-dependent cancer cell proliferation in androgen-independent prostate cancer cells (Yang et al., 2017). Moreover, combination of NPV-BEZ-235 with the SMO inhibitor NVP-LDE-225 demonstrated enhanced efficacy than single agents in the inhibition of self-renewal and tumorigenicity of pancreatic CSCs (Sharma et al., 2015).

Upregulation of PI3K signaling has been linked to acquired resistance to SMO inhibitors for the re-expression of GLI1 in medulloblastoma (Buonamici et al., 2010), and proposed as a potential resistance mechanism for other tumors such as esophageal cancer (Wang et al., 2012), implying that a combinatorial approach targeting both canonical (with SMO inhibitors) and non-canonical GLI activation (via PI3K inhibitors) could delay tumor resistance (Buonamici et al., 2010; Dijkgraaf et al., 2011).

\section{TGF- $\beta$ Signaling}

Transforming growth factor $\beta$ (TGF- $\beta$ ) signaling exerts important functions during embryonic development and homeostasis of adult tissues. During carcinogenesis, TGF$\beta$ signaling can act both as tumor suppressor or oncogene depending on tumor type and stage (David and Massagué, 2018). An increasing number of reports shows that TGF- $\beta$ signaling can interact with the HH-GLI pathway downstream of SMO. Dennler et al. (2007) were the first to demonstrate that TGF- $\beta$ pathway regulates GLI transcription factors in a SMO-independent manner in human normal fibroblasts and keratinocytes, as well as in PDAC and breast cancer cells. The induction of GLI2 by TGF- $\beta$ occurs through a SMAD3dependent mechanism and mediates subsequent activation of GLI1. Interestingly, TGF- $\beta$ signaling is required for GLI expression and proliferation of cyclopamine-resistant pancreatic carcinoma cells. In these cells, treatment with an antagonist of the TGF- $\beta$ receptor (T $\beta R I$ ) reduces GLI2 mRNA levels and cell proliferation (Dennler et al., 2007). A further study showed that GLI2 is a direct transcriptional target of TGF- $\beta$, that induces a rapid increase of GLI2 expression independently of PTCH/SMO, through the cooperation of SMAD3 and $\beta$-catenin on GLI2 promoter (Dennler et al., 2009). In addition, TGF- $\beta$ is able to stimulate GLI1 activity in cancer cells and to induce a subset of TGF- $\beta$-inducible target genes, including BCL2, IL7 and Cyclin D1 (Nye et al., 2014). GLI1 interacts with SMAD proteins to modulate TGF- $\beta$-induced gene expression dependent 
on p300/CREB-binding protein-associated factor (PCAF) (Nye et al., 2014).

Several mouse models have shown that TGF- $\beta$ signaling is also critical for Hh-mediated carcinogenesis. For instance, in a model of pancreatic cancer, SMO-independent Glil activation promotes transformation and requires both TGF- $\beta$ and KRAS signaling (Nolan-Stevaux et al., 2009). Similarly, TGF- $\beta$ signaling appears to be required in a mouse model of Smo-driven BCC, where inhibition of TGF- $\beta$ by T $\beta R I$ antagonist SD208 significantly reduces tumor burden and increases infiltration of lymphocytes. The relevance of this finding is mirrored in human BCCs, which often harbor activation of both HH and TGF- $\beta$ signaling, as shown by increased phosphorylation of SMAD2 and SMAD3 (Fan et al., 2010).

Non-canonical activation of GLI by TGF- $\beta$ plays a driving role in EMT and invasion of different tumors. In melanoma, high GLI2 levels are associated with a metastatic phenotype with appearance of mesenchymal features both in vitro and in vivo. Consistently, GLI2 silencing reduces invasion of extracellular matrix in vitro and bone metastasis in mice (Alexaki et al., 2010). In a metastasis model of breast cancer cells MDA-MB-231, SMO-independent induction of GLI2 is required for TGF- $\beta$ to stimulate the expression of parathyroid hormone-related protein (PTHrP), an important osteolytic factor in bone metastasis (Johnson et al., 2011). In these cells, SMO is not detectable and the SMO inhibitor cyclopamine fails to repress GLI2. Furthermore, blocking $\mathrm{HH}$ signaling in metastatic breast cancer cells with the repressor form of GLI2 reduces endogenous and TGF$\beta$-stimulated PTHrP expression and bone metastasis in mice (Johnson et al., 2011), supporting the role of GLI2 downstream of TGF- $\beta$ in driving metastasis.

The interaction between TGF- $\beta$ and HH-GLI signaling is also associated to cancer cell stemness and chemoresistance. Indeed, recurrent ovarian tumors are enriched in CSCs that express high levels of GLI2 and components of TGF- $\beta$ pathway, such as the co-receptor endoglin (CD105). Interestingly, GLI2 inhibition sensitizes cells to cisplatin treatment and reduces tumor proliferation, and both CD105 and GLI2 are proposed as promising targets to overcome resistance (Steg et al., 2012). In colorectal cancer, hypoxia-inducible factor (HIF$1 \alpha)$ and cancer-associated fibroblasts (CAFs)-secreted TGF$\beta 2$ converge to induce strong expression of GLI2 in CSCs, independently of HH signaling (Tang et al., 2018). HIF-1 $\alpha /$ TGF$\beta 2 /$ GLI2 expression promotes stemness and chemoresistance in colorectal cancers and is associated with patient relapse following chemotherapy. Interestingly from a therapeutic point of view, combined inhibition of both TGF- $\beta$ with SD208 and GLI2 with GANT61 restores chemoresistance, reducing both self-renewal and survival of CSCs (Tang et al., 2018).

\section{PKC Signaling}

The protein kinase $\mathrm{C}(\mathrm{PKC})$ is a serine/threonine kinase consisting of three members: calcium-dependent conventional PKC (cPKC; isoforms $\alpha, \beta \mathrm{I}, \beta \mathrm{II}$ and $\gamma$ ), calcium-independent novel PKC (nPKC; isoforms $\delta, \varepsilon, \eta$ and $\theta$ ), and calciumindependent atypical PKC (aPKC; isoforms $\zeta$ and $\mathrm{s} / \lambda$ ). The role of PKC $\alpha$ and PKC $\delta$ in controlling GLI activity is controversial.
Constitutive activation of $\mathrm{PKC} \alpha$ reduces the transcriptional activity of GLI1, whereas that of PKC $\delta$ enhances GLI1 transcriptional activity in HEK-293T cells independent of MAPK signaling (Neill et al., 2003). In contrast, another report showed that in NIH3T3 cells and in human hepatoma Hep3B cells PKC $\alpha$ increases GLI1 transcriptional activity through MEK1/2-ERK1/2 pathway activation (Cai et al., 2009). Conversely, wild-type and constitutive active PKC $\delta$ functions as negative regulator of $\mathrm{HH}$ pathway, reducing GLI1 mRNA level and transcriptional activity. PKC $\delta$ co-immunoprecipitates with GLI1, but the interaction does not involve its kinase activity (Cai et al., 2009). Riobò et al. (2006a) found that PKC $\delta$ mediates the phorbol esters activation of Hh pathway, increasing Glil transcriptional activity through MEK1/2 activation.

On the other hand, aPKCl/ $\lambda$ activates GLI1 downstream of SMO, through phosphorylation of two residues (Ser243 and Thr304) in the zinc finger DNA binding domain of GLI1, leading to increased DNA binding and transcriptional activity (Atwood et al., 2013). Furthermore, GLI1 promotes the transcription of the gene encoding for aPKCl, contributing to form a positive GLI-aPKCı regulatory loop. Interestingly, activated $\mathrm{aPKC} / \lambda$ is upregulated in BCC resistant to the SMO inhibitor vismodegib and targeting $\mathrm{aPKC} / \lambda$ suppresses the $\mathrm{HH}$ pathway and growth of resistant BCC cell lines (Atwood et al., 2013). In addition, Justilien et al. (2014) demonstrated that PKCı phosphorylates SOX2, a transcriptional regulator of stemness, promoting the autonomous transcription of $\mathrm{HH}$ ligand. The functional interaction between $\mathrm{PKCl}$ and SOX2 coordinately drives growth and maintenance of lung squamous cell carcinoma stem-like cells.

\section{DYRK1 and 2}

Dual-specificity tyrosine phosphorylation-regulated kinases (DYRKs) are serine, threonine and tyrosine kinases containing a DYRK-homology box. Among the five DYRK members, DYRK1A and DYRK1B play a dual role in GLI regulation, whereas DYRK2 is mainly an inhibitor. Overexpression studies indicated that DYRK1A can act as a positive regulator of GLI1, promoting its nuclear translocation (Mao et al., 2002; Shimokawa et al., 2008) through direct phosphorylation of GLI1 nuclear localization clusters in the N-terminus (Ser102/104/130/132) and at Ser408 (Schneider et al., 2015; Ehe et al., 2017). In contrast, DYRK1A is also able to induce GLI1 degradation by repressing the transcriptional co-activator megakaryoblastic leukemia 1 (MKL1), independent of upstream PTCH/SMO signaling. The final decision about which signaling prevails appears to be cell-type specific or depends on DYRK1A and GLI1 expression levels (Schneider et al., 2015).

DYRK1B can act as activator or repressor. It inhibits GLI2 function and promotes the formation of the GLI3 repressor form (Lauth et al., 2010). Conversely, DYRK1B can increase GLI1 activity, and its inhibition has been shown to repress GLI1 expression in both SMO-inhibitor sensitive and resistant cells (Gruber et al., 2016). Another study showed that DYRK1B can promote AKT-mediated GLI1 stability (Singh et al., 2017). The other DYRK member, DYRK2, phosphorylates Gli2 on two conserved Serine residues (at position Ser385 
and Ser1011), promoting its proteasome-dependent degradation (Varjosalo et al., 2008).

\section{AMPK}

$5^{\prime}$ Adenosine monophosphate (AMP)-activated protein kinase (AMPK) is a serine/threonine kinase that supervises cellular energy status in response to the nutrient supply and environmental conditions; it is activated by increased AMP/ATP ratio and controls different energetic processes (i.e., growth, metabolism, protein synthesis). Activated AMPK phosphorylates GLI1 at Serine/Threonine residues (Ser102, Ser408 and Thr1074), decreasing both transcriptional activity and protein stability (Li et al., 2015). However, another report indicates that only phosphorylation at Ser408 is critical for GLI1 degradation and appears to reduce $\mathrm{HH}$-driven cell growth in human medulloblastoma (Di Magno et al., 2016). Furthermore, AMPK has been shown to increase GLI1 cytoplasmic localization and to promote its interaction with the E3 ubiquitin ligase $\beta$-TrCP, leading to GLI1 degradation by the proteasome (Zhang et al., 2017).

AMPK can also activate the HH-GLI pathway, acting downstream of SMO to stimulate metabolic reprogramming toward glycolysis in adipocytes, and increases glucose uptake (Teperino et al., 2012). In addition, another report showed that AMPK mediates a non-canonical HH signaling that promotes polyamine metabolism, by activating an axis that leads to translation of ornithine decarboxylase (ODC) (D'Amico et al., 2015). In response to $\mathrm{Hh}$ activation, AMPK phosphorylates and activates the zinc finger protein CNBP (cellular nucleic acid-binding protein), which increases its association with Sufu, followed by CNBP stabilization, ODC translation, and polyamine biosynthesis. Interestingly, targeting this axis efficiently blocks Hh-dependent proliferation of medulloblastoma cells in vitro and in vivo (D'Amico et al., 2015). These findings suggest that AMPK can favor or inhibit tumorigenesis in a contextdependent manner. Therefore, further preclinical and clinical studies are required to warrant the use of AMPK modulators in anti-cancer therapy.

\section{Oncogenic Drivers}

Activation of GLI transcription by oncogenes represents an additional mode of SMO-independent modulation. For instance, the Ewing Sarcoma/Friend Leukemia Integration 1 (EWS/FLI1) fusion oncogene, that characterizes Ewing Sarcoma Family Tumors (ESFT), has been shown to induce GLI1 transcription via direct binding to GLI1 promoter, with a consequent increase in the expression of activated GLI1 protein (Zwerner et al., 2008; Beauchamp et al., 2009). Indeed, ESFT show deregulated expression of GLI1 (Joo et al., 2009) and this appears critical for the ESFT phenotype, since genetic or pharmacological inhibition of GLI1 reduces the EWS/FLI1 transformation activity, impairs in vitro cell proliferation and colony formation, and abrogates in vivo tumor growth (Zwerner et al., 2008; Beauchamp et al., 2009).

In addition, the SRY-related high mobility group (HMG) box transcription factor SOX9 has been reported to regulate GLI1 by suppressing its association with $\beta-\operatorname{TrCP}$ and subsequent ubiquitination (Deng et al., 2015). Indeed, SOX9 binds the $\mathrm{N}$-terminal F-box domain of $\beta$ - TrCP through its transactivation domain and tethers $\beta$-TrCP into the nucleus, protecting nuclear GLI1 from degradation. This mechanism is critical for promoting SOX9-dependent CSC-like properties of pancreatic cancer cells (Deng et al., 2015).

Han and colleagues showed that the Forkhead box C1 (FOXC1) stimulates SMO-independent $\mathrm{HH}$ signaling in basallike breast cancer (BLBC) by binding GLI2 (Han B.C. et al., 2015). This interaction occurs through the N-terminal domain of FOXC1 and is predicted to allosterically open the DNA binding domain of GLI2. This favors the transcriptional activity of GLI2, leading to increased CSC properties through the induction of a stem cell-like signature in BLBC cells. In support of this, increased FOXC1 levels have been detected in SMO inhibitor-resistant cells, whereas its depletion reverts the resistant phenotype.

Further, Yoon et al. (2013) showed that the oncogene c-MYC enhances the expression of GLI1 in Burkitt lymphoma cells, by direct interaction with the E-box (CANNTG) within the $5^{\prime}$ regulatory region of GLI1. Recently, the beta subunit of the IKK complex $(\operatorname{IKK} \beta)$, which is induced in response to $\mathrm{TNF} \alpha$, has been reported to increase GLI1 protein levels and transcriptional activity in diffuse large B-cell lymphoma (Agarwal et al., 2016). The authors identified 8 IKK $\beta$-dependent phosphorylation sites within the C-terminus of GLI1, which include a cluster of 6 Serine residues (S543-S548), a Serine residue at position 1071 and a Threonine residue at 1074 . IKK $\beta$-mediated phosphorylation of these sites prevents the association of GLI1 with the E3 ubiquitin ligase ITCH responsible for GLI1 degradation, thus favoring its stabilization (Agarwal et al., 2016).

Non-canonical GLI regulation by oncogenes has been also related to the development of resistance toward SMO inhibitors in cancer. By using a multidimensional genomic analysis of mouse and human drug-resistant BCCs, Whitson et al. (2018) found that the serum response factor (SRF) and its transcriptional co-factor MKL1 form a protein complex with GLI1 that enhances the transcription of HH-pathway target genes. Further, SRFMKL1 also directly regulates GLI1 and GLI2 expression by binding to their $5^{\prime}$-untranslated regions ( $5^{\prime}$-UTR), thus inducing amplification of GLI1 transcriptional activity and drug-resistant BCC growth (Whitson et al., 2018).

The oncogenic wild-type p53-induced phosphatase 1 (WIP1) has been shown to cooperate with $\mathrm{HH}$ signaling to increase tumor formation in SHH-dependent medulloblastoma (Doucette et al., 2012). Similarly, mice overexpressing WIP1 under the control of the Neurod2 promoter present increased proliferation in the external cellular layer of the cerebellum through activation of the endogenous $\mathrm{Hh}$ signaling (Wen et al., 2016). Interestingly, medulloblastoma incidence increases when ND2:WIP1 mice are crossed with SmoA1, whereas Wip1 knockout suppresses MB formation in two Hh-dependent mouse model of medulloblastoma (Wen et al., 2016). These studies demonstrated an interplay between Wip1 and Hh signaling in medulloblastoma development. Our group identified the mechanism of regulation of GLI by WIP1 in melanoma cells. We found that WIP1 enhances GLI1 nuclear localization, protein 
stability and transcriptional activity, without affecting GLI2 nor GLI3 (Pandolfi et al., 2013). WIP1 phosphatase activity appears to modulate GLI1 transcriptional activity, suggesting a direct dephosphorylation of GLI1 by WIP1, although evidence of a direct dephosphorylation is still lacking (Pandolfi et al., 2013).

Non-canonical activation of the $\mathrm{HH}$ pathway can also be mediated by the interaction of the androgen receptor (AR) with the GLI transcription factors. A recent report showed that transcriptionally active AR increases GLI transcriptional activity in prostate cancer cells. AR binds to the GLI3 protein processing domain at the C-terminus, impairing GLI3 ubiquitination and degradation (Li et al., 2018). AR prevents the formation of GLI3 repressor and stabilizes its activator form, promoting $\mathrm{HH}$ signaling. A truncated polypeptide of 270 amino acids derived from GLI2 and containing the AR binding site, is able to compete with GLI3 for binding to AR, inhibiting HH-GLI signaling in prostate cancer cells (Li et al., 2018).

\section{Tumor Suppressors and miRNAs: Negative Regulators of the GLI}

In addition to the various oncogenic signals that positively influence GLI activity, increasing evidence suggests that tumor suppressive signals play also a crucial role in the control of GLI function and activity.

The tumor suppressor p53 controls cellular homeostasis and protects cells from tumorigenic events by inducing apoptosis, cellular senescence and cell cycle arrest in response to different cellular stress signals, such as DNA damage, hypoxia or oncogenic activation. Importantly, over half of human cancers are characterized by loss-of-function mutations in the TP53 gene (Bieging et al., 2014). Several studies pointed to a negative regulation of GLI by p53. Stecca and Ruiz i Altaba (2009) reported that p53 restrains GLI1-driven neural stem cell selfrenewal, and glioblastoma cell growth and proliferation. p53 represses GLI1 activity, nuclear localization and levels. p53 has been also found to affect the phosphorylation status of the GLII $\Delta \mathrm{N}$ isoform, acting either directly or indirectly to antagonize a protein phosphatase, thus favoring the inactive and more stable state of GLI1 $\Delta \mathrm{N}$ (Stecca and Ruiz i Altaba, 2009). p53 was also shown to inhibit GLI1 levels and function by inducing the transcriptional activation of PCAF in response to DNA damage (Mazzà et al., 2013). The intrinsic E3-ligase activity of PCAF leads to poly-ubiquitination in the C-terminus of GLI1 and subsequent degradation by the proteasome, thus attenuating the mitogenic and pro-survival properties of GLI1 in medulloblastoma (Mazzà et al., 2013). In another study, p53 was shown to sequester the TATA box binding protein (TBP)-associated factor 9 (TAF9), which is a component of the PCAF histone acetylase complex, and to prevent its association with GLI1 and GLI2 proteins (Yoon et al., 2015). Indeed, TAF9 was shown to physically interact with GLI1 at the residue L1052 in the transactivation domain in rhabdomyosarcoma and osteosarcoma cells. This interaction has been reported to enhance GLI-mediated transactivation of a specific pattern of target genes and, thus, transformation (Yoon et al., 2015).
The adaptor protein Numb is an evolutionary conserved protein implicated in cell fate specification, endocytosis, migration and stem cell maintenance (Gulino et al., 2010). Accumulating evidence suggests a role of Numb as a tumor suppressor in a variety of cancers. Loss of Numb has been described in medulloblastoma, where its downregulation has been associated with the hyperactivation of $\mathrm{HH}$ signaling that occurs as a consequence of GLI1 accumulation, leading to in vitro transformation and enhanced tumor growth and metastasis. Indeed, Numb acts as an adaptor protein that binds the E3 ubiquitin ligase Itch and releases it from its self-inhibitory conformation. Then, the catalytically active Itch interacts with a Serine residue at position 1060 (S1060) in a proline-rich motif in the C-terminal tail of GLI1, and recruits it into a complex with Numb. This results in the ubiquitination and proteasome-dependent degradation of GLI1 (Di Marcotullio et al., 2006, 2011). Consistent with these findings, HH-dependent medulloblastomas show an inverse correlation with levels of the Numb isoform p66, which is involved in neural differentiation and whose downregulation results in enhanced medulloblastoma CSC features (Abballe et al., 2018).

The tumor suppressor SNF5, a chromatin remodeling protein representing a core subunit of the ATP-dependent SWI-SNF complex, has been also shown to restrain the activity of $\mathrm{HH}$ signaling. Affinity purification-mass spectrometry performed in a HH-responsive mouse testicular epithelial cell line led to the identification of SNF5 among the top interactors of GLI1 (Jagani et al., 2010). This physical interaction has been reported to repress the activity of $\mathrm{HH}$ signaling via the control of chromatin structure at GLI1 target promoters. Notably, loss of SNF5, observed in malignant rhabdoid tumors, has been associated with derepression of transcriptional activity at GLI1 locus and hyperactivation of $\mathrm{HH}$ signaling, which contributes to cancer formation (Jagani et al., 2010).

Small non-coding micro RNAs (miRNAs) are responsible for post-transcriptional regulation of gene expression via binding to $3^{\prime}$-UTRs of target mRNAs, resulting in their degradation or inhibition of translation. miRNAs are involved in several biological processes, such as proliferation, differentiation, development, and metabolism, and have been implicated in tumorigenesis by targeting developmental pathways involved in tumor formation (Ling et al., 2013; Oliveto et al., 2017). With regard to $\mathrm{HH}$ signaling, miRNAs appear to modulate the expression of GLI independently of PTCH/SMO. A previous study by Ferretti et al. (2008) showed that the tumor suppressor miR-324-5p acts as a negative regulator of $\mathrm{HH}$ signaling in cerebellar granule cell precursors (CGCP) by targeting and functionally suppressing GLI1 mRNA. Chen et al. (2017) reported that derepression of miR-361 expression in prostate carcinoma cells directly inhibits GLI1 expression through the binding to the 3'-UTR of GLI1 itself, thus restraining the malignant growth and invasiveness of prostate cancer. Downregulation of miR361-3p has been also observed in retinoblastoma tissues. When overexpressed, miR-361-3p strongly restrains cell proliferation and CSC self-renewal of retinoblastoma cells, by repressing GLI1 and GLI3 (Zhao and Cui, 2019). miR-326 is another negative modulator of $\mathrm{HH}$ signaling, and it acts by inhibiting GLI2. Using 
a genome-wide expression profiling in embryonic lung explant cultures, Jiang and co-workers reported that miR-326 is part of a negative feedback loop in regulating the activity of $\mathrm{HH}$ signaling during lung development (Jiang et al., 2014). Indeed, while $\mathrm{HH}$ signaling induces the expression of miR-326 and of its host gene $\beta$-arrestin (Arrb1), miR-326 suppresses the expression of GLI2 (Jiang et al., 2014). Downregulation of miR-326 has been also recently identified as a critical feature of CSCs isolated from a mouse model of Shh-dependent medulloblastoma. Indeed, re-expression of miR-326 and Arrb1, which acts as a scaffold protein that facilitates the recruitment of p300 to target histones with consequent transcription activation, have been shown to induce a more differentiated phenotype by inhibiting HH-GLI signaling at multiple levels. First, miR-326 directly represses GLI2 by binding to its $3^{\prime}$-UTR, thus impairing the expression of several HH target genes; second, Arrb1 facilitates p300-mediated acetylation of GLI1 at K518, further inhibiting $\mathrm{HH}$ signaling (Miele et al., 2017).

\section{Epigenetic Modulators}

Beside genetic modifications and other oncogenic inputs, alterations of the epigenetic machinery appear critical for tumor development. Recently, several lines of evidence pointed to an epigenetic control of $\mathrm{HH}$ signaling that occurs downstream of SMO and SUFU.

\section{Bromodomain Proteins}

Members of the bromo- and extra-terminal domain (BET) family of chromatin adaptors bind acetyl-lisine residues on open chromatin and facilitate gene transcription at super-enhancers through their interaction with the positive transcription elongation factor $\mathrm{b}(\mathrm{P}-\mathrm{TEFb})$ and RNA polymerase II (PolII) (Mujtaba et al., 2007). Recently, the bromodomain-containing protein 4 (BRD4) has been reported to regulate $\mathrm{HH}$ signaling by directly binding to GLI1 and GLI2 promoters (Tang et al., 2014). Of note, its depletion has been associated with reduced survival of medulloblastoma CSC in vitro and tumor growth of a $\mathrm{Ptch}^{+/-}$derived medulloblastoma allograft in vivo (Long et al., 2014). BET proteins have been also associated to GLI-dependent pancreatic cancer growth and stromal remodeling. Indeed, the antitumor effects of their inhibition occur most likely through cell-extrinsic mechanisms in the stromal compartment that affect GLI1 expression and alter the secretome of CAFs, leading to the suppression of PDAC growth and tumor-sphere formation in a paracrine manner (Yamamoto et al., 2016). However, BET proteins also physically associate with GLI proteins in PDAC cells in order to allow their occupancy on target gene promoters, denoting the existence of different mechanisms of regulation of the $\mathrm{HH}-\mathrm{GLI}$ signaling pathway in PDAC tumors (Huang et al., 2016).

\section{Chromatin Remodelers}

Acetylation represents a crucial transcriptional event in various developmental and differentiation processes, being one of the modifications that impact chromatin remodeling and transcription, and its deregulation is involved in the development of several tumors. Histone acetyltransferases (HATs) and histone deacetylases (HDACs) catalyze, respectively, the addition or the removal of an acetyl group on lysine residues within the $\mathrm{N}$-terminal histone tails as part of gene regulation (Bannister and Kouzarides, 2011). Several lines of evidence highlight the importance of HDACs in controlling the activity of $\mathrm{HH}$ signaling. A previous study showed that acetylation of Gli1 and Gli2 proteins inhibits their DNA binding ability, and that class I HDACs enhance the transcriptional activity of Gli1 through deacetylation of a lysine residue at position 518 (K518) (Canettieri et al., 2010). In physiological settings, the function of Gli1 is maintained through an integrated mechanism involving HDAC1 and $\mathrm{REN}_{K C T D 11}$, which is an adaptor subunit of the Cullin-3 (Cul3)-based ubiquitin ligase complex, that targets HDAC1 for ubiquitination and subsequent proteasome-degradation, in order to ensure proper development and prevent tumorigenesis (Canettieri et al., 2010). Subversion of this mechanism due to HDAC overexpression or loss of REN, has been shown to induce persistent deacetylation of Gli1, leading to CGCP transformation and subsequent medulloblastoma growth (Canettieri et al., 2010). In support of this, selective inhibition of $\mathrm{HDAC} 1 / 2$ results effective in inhibiting $\mathrm{HH}$ signaling and reducing tumor growth in Shh-dependent medulloblastoma mouse models through increased acetylation of Gli1 at Lys518 (Coni et al., 2017). Recently, Gruber and co-workers showed that inhibition of class I HDACs represses the HH-GLI signaling in Ptch1-deficient mouse medulloblastoma cells not only by decreasing the DNA binding capacity of Gli1, but also contributing to efficient Gli3 repressor formation, thus implying for the first time a direct role of acetylation in Gli processing (Gruber et al., 2018). Indeed, previous reports linked the repressor activity of GLI3 to the Ski-dependent recruitment of HDAC (Dai et al., 2002), although whether and how it occurs was not addressed in this study.

In addition to $\mathrm{HDAC} 1 / 2$, the class II protein HDAC6 is found upregulated in medulloblastoma tumors, and its inhibition shows tumor suppressive effects in preclinical models of Shhmedulloblastoma. Remarkably, HDAC6 effects seem to be independent of GLI acetylation, and to occur most likely through the transcriptional control of GLI2 expression and stabilization of GLI3 protein (Dhanyamraju et al., 2015). In line with these findings, a recent study in multiple myeloma revealed that hyperacetylation of GLI1 through pharmacological inhibition of class I and II HDACs leads to reduced tumor survival by decreasing nuclear accumulation and transcriptional activity of GLI1, and accelerating its proteasomal degradation (Geng et al., 2018).

Histone acetyltransferases have been also implicated in the regulation of non-canonical $\mathrm{HH}$ signaling. First, it has been shown that the HAT co-activator p300 functions as a crucial transcriptional checkpoint during morphogen-dependent development (Coni et al., 2013). Indeed, p300 has been shown to acetylate GLI2 at the conserved Lysine residue 757 (K757), preventing GLI2 recruitment to chromatin and thus inhibiting $\mathrm{HH}$ target gene expression (Coni et al., 2013). Second, PCAF plays opposing roles in modulating GLI1 activity, depending on microenvironmental conditions (Malatesta et al., 2013). Indeed, PCAF acts as a transcriptional cofactor of GLI1 in permissive conditions by increasing $\mathrm{H} 3 \mathrm{~K} 9$ acetylation at GLI target gene 
promoters, leading to brain tumor cell growth (Malatesta et al., 2013). Conversely, in non-permissive situations (i.e., genotoxic stress) PCAF switches to apoptotic activity and restrains $\mathrm{HH}$ functions and oncogenic properties by directly binding to GLI1 and promoting its ubiquitination and proteolysis via the E3 ligase activity (Mazzà et al., 2013).

\section{Protein Arginine Methyltransferases (PRMT)}

Members of the protein arginine methyltransferase (PRMT) family regulate several cellular processes, including gene transcription, DNA repair, mRNA splicing and signal transduction. Aberrant activity of PRMT has been reported in several tumors (Yang and Bedford, 2013). PRMT1 can promote the transcriptional activity of GLI1 by inducing its methylation at residue Arg597, thus increasing binding of GLI1 to the promoter of its targets. Abrogation of GLI1 methylation reduces its oncogenic functions in PDAC (Wang et al., 2016). Studies in SHH-expressing gastric cancer cells and small cell lung cancer showed that GLI1 is methylated at three Arginine residues $(515,990$ and 1018) by the methylosome protein 50 (MEP50)/PRMT5 complex. Methylations at Arg990 and Arg1018 act to inhibit the interaction of GLI1 with the E3 ligase complex ITCH/NUMB, leading to GLI1 stabilization, nuclear accumulation and transcriptional activation (Abe et al., 2019). The authors show also a positive correlation between the expression of MEP50/PRMT5 and that of GLI1 target genes in several $\mathrm{HH}$-dependent cancers, and demonstrate that targeting of MEP50/PRMT5 complex may synergize with SMO inhibitors in suppressing cancer cell proliferation and invasion (Abe et al., 2019). By contrast, PRMT5 has been reported also to negatively affect GLI1 activation in endocrine organs (Gurung et al., 2013). Indeed, the tumor suppressor Menin was found to bind to GLI1 promoter and recruits PRMT5 to repress GLI1 expression, at least partially through the PRMT5-catalyzed histone arginine methylation on histone H4 (H4R3m2). Thus, mutations in the MEN1 gene result in activation of GLI1 through increased binding of transcriptionally active GLI1 at its promoter, leading to the development of neuroendocrine tumors (Gurung et al., 2013) (Figure 3).

\section{IMPLICATIONS FOR CANCER THERAPY}

To date, most of the efforts to inhibit HH-GLI signaling have been directed on the development of SMO inhibitors (SMOi), such as vismodegib (GDC-0449), sonidegib (NPV-LDE-225), saridegib (IPI-926), BMS-833923, glasdegib (PF-04449913) and taladegib (LY2940680) (Pietrobono and Stecca, 2018). These SMOi show improved potency, pharmacokinetics and tolerability compared to the natural steroidal alkaloid SMO antagonist cyclopamine, enhancing their clinical utility. The US Food and Drug Administration (FDA) and European Medicines Agency (EMA) have approved both vismodegib and sonidegib for treatment of locally advanced or metastatic BCC (LoRusso et al., 2011; Sekulic et al., 2012; Dummer et al., 2016). Furthermore, some of these SMOi have been successfully used for treating medulloblastoma, BCC and other advanced solid tumors (Rodon et al., 2014; Wagner et al., 2015; Pietanza et al., 2016; Stathis et al., 2017) as well as hematological malignancies (Martinelli et al., 2015; Savona et al., 2018).

However, acquisition of resistance due to specific missense mutations at SMO level (i.e., SMO-D437H) represents the major challenge to the success of therapies, as well documented in BCC (Atwood et al., 2015; Pricl et al., 2015; Sharpe et al., 2015). This limitation led to the development of novel SMOi with activity toward the mutated variants of SMO, such as MRT-92 (Hoch et al., 2015; Pietrobono et al., 2018). Besides, clinical trials with SMO antagonists in most solid tumors have failed most likely because in these tumors SMO is not the main oncogenic driver, and alternative oncogenic events could be responsible for SMOindependent GLI activation (i.e., RAS-ERK, PI3K-AKT-mTORS6K1 signaling, p53 loss, epigenetic alterations, etc.). In such cases, direct targeting of GLI might represent the best choice to improve the antitumor activity of these drugs.

In the last few years, several GLI inhibitors have been developed and tested. Some of them have been shown to directly interfere with DNA binding ability of GLI, including GANT58 and 61 (Lauth et al., 2007) and Glabrescione B (Infante et al., 2015), whereas others, such as HPI1-4 (Hyman et al., 2009) and ATO (Kim et al., 2010; Beauchamp et al., 2011), have been reported to modulate GLI processing and activation, trafficking and/or ciliary accumulation. However, with the exception of ATO, which is not specific for GLI and showed in vitro cytotoxicity (Yedjou and Tchounwou, 2007), none of these GLI inhibitors are good candidates for clinical studies.

Targeting alternative pathways responsible for non-canonical GLI activation together with SMO inhibition could therefore represent an intriguing strategy to allow the complete eradication of GLI-dependent tumors. In this section we provide examples of preclinical or clinical studies focused on combinatorial therapies with $\mathrm{HH}$ antagonists and inhibitors of the above-described oncogenic signaling pathways.

The RAS-RAF-MEK pathway is among the compensatory mechanisms that sustain HH-GLI signaling beyond SMO. Several preclinical studies demonstrated synergic effects between SMO inhibitors and MEK inhibitors in GLI-dependent tumors. For instance, co-administration of the SMO inhibitor SANT-1 with the MEK1 inhibitor PD325901 in prostate cancer cells characterized by hyperactivation of MAPK signaling, has been shown to reduce prostate cancer cell growth more than either single agent alone (Gioeli et al., 2011). Likewise, dual blockade of $\mathrm{HH}$ (with the SMOi cyclopamine) and MAPK signaling (with the MEKi U0126) showed increased efficacy in reducing proliferation and survival of cholangiocarcinoma cells (Jinawath et al., 2007). Furthermore, the existence of non-canonical activation of $\mathrm{HH}$ signaling by the MEK1/RSK2 axis responsible for GLI2 stabilization in multiple myeloma strongly supports the development of novel therapeutic strategies targeting both pathways. Indeed, simultaneous inhibition of GLI with GANT58 and RSK2 with SL0101 has been reported to synergistically reduce GLI2 levels, enhancing apoptosis of multiple myeloma cells (Liu et al., 2014). Hyperactivation of the MAPK signaling pathway has been also recently related to the acquisition of resistance to 
vismodegib in medulloblastoma by promoting a niche of SMOiinsensitive cells in which the RAS-RAF-MEK pathway sustains tumor proliferation, while $\mathrm{HH}$ pathway becomes dispensable (Zhao et al., 2015). In line with this, previous work by Ji and co-workers showed that pharmacological inhibition of MEK1/2 with UO126 reduced GLI activation in PDAC cells resistant to SMOi, thus representing an efficient strategy to contrast the non-canonical activation of $\mathrm{HH}$ signaling (Ji et al., 2007).

Given that activation of various RTKs, including EGFR, converges on the RAS-RAF-MEK-ERK pathway, is not surprising that their inhibition in combination with that of $\mathrm{HH}$ signaling could overcome or delay resistance mechanisms observed after prolonged treatment with SMOi. EGFR signaling has been shown to cooperate with $\mathrm{HH}$ signaling in various contexts (Palma and Ruiz i Altaba, 2004; Palma et al., 2005; Schnidar et al., 2009; Eberl et al., 2012) and to induce GLI activation through the MAPK pathway (Kasper et al., 2006). In support of this, several preclinical studies in the last decade have been focused on combining SMOi with RTK inhibitors, such as those of EGFR, in order to improve the antitumor response. For instance, combination treatment with the SMOi saridegib and the EGFR inhibitor cetuximab abrogates tumor growth and delays tumor recurrence in mouse xenograft models derived from metastatic head and neck squamous cell carcinoma (Bowles et al., 2016). Likewise, co-administration of GANT61 with erlotinib (an EGFR inhibitor) has been reported to impair tumor initiating properties of pancreatic cancer cells, and to reduce tumor growth in $\mathrm{HH}$ driven BCC mouse models (Eberl et al., 2012). Treatment with SMOi has been also shown to enhance the efficacy of EGFR inhibitors in non-small cell lung cancer (Ahmad et al., 2013), prostate cancer (Mimeault et al., 2006, 2007) and glioblastoma CSCs (Eimer et al., 2012).

PI3K-AKT-mTOR signaling represents a promising therapeutic strategy for GLI-dependent tumors, given its involvement in enhancing transcriptional activity and increasing nuclear localization of GLI. Sharma et al. (2015) demonstrated the efficacy of combining the SMO inhibitor sonidegib with the dual PI3K/mTOR inhibitor NVP-BEZ-235 on pancreatic CSC survival and tumorigenicity. Similarly, combined inhibition of GLI with GANT61 and mTOR with rapamycin has been reported to improve the effects of single agent alone on pancreatic cancer cell viability and CSC self-renewal, and to suppress in vivo growth of pancreatic cancer xenografts (Miyazaki et al., 2016). In another study, Wang et al. (2012) showed that inhibition of HH pathway with vismodegib in esophageal adenocarcinoma cell lines and mouse xenografts has a more potent inhibitory effect in presence of the mTOR inhibitor everolimus (RAD001), implying that $\mathrm{PI} 3 \mathrm{~K} / \mathrm{mTOR}$ could be responsible for the acquisition of resistance of esophageal adenocarcinoma to SMOi. Consistently, treatment with the PI3K inhibitor GDC-0941 strongly inhibited the growth of vismodegib-insensitive tumor models (Dijkgraaf et al., 2011). By applying gene expression profiling of sonidegib-resistant versus sonidegib-sensitive medulloblastomas, Buonamici and collaborators identified a number of PI3K target genes that were enriched only in resistant samples, suggesting that hyperactivation of this pathway could contribute to the acquisition of resistance. To support this, authors provided evidence that co-administration of the PI3K inhibitor NVPBKM120 and sonidegib significantly delays the onset of resistance and tumor regrowth, without inhibiting growth of already established resistant tumors (Buonamici et al., 2010). Combination of sonidegib and NVP-BKM120 has been also shown to abrogate glioblastoma tumor growth by inducing mitotic catastrophe and apoptosis (Gruber-Filbin et al., 2013). Thus, the use of dual HH and PI3K-AKT-mTOR inhibitors (Yang et al., 2015) could represent a promising therapeutic approach to counteract the emergence of resistance in those tumors.

Given the involvement of TGF- $\beta$ pathway in the activation of GLI proteins independent of PTCH/SMO, combined treatment modalities with inhibitors of SMO and TGF- $\beta$ could be beneficial for GLI-dependent tumors. For instance, Dennler et al. (2007) demonstrated that pharmacologic blockade of TGF- $\beta$ signaling in SMOi-resistant PDAC cells expressing high levels of GLI, reduces GLI2 expression with a subsequent repression of cancer cell proliferation. Furthermore, a recent study reported that combined inhibition of TGF- $\beta$ with SD208 and of GLI with GANT61 could reverse chemoresistance in colorectal cancer, and prevent CSC relapse in patients after chemotherapy (Tang et al., 2018).

Combined inhibition of $\mathrm{HH}$ signaling and $\mathrm{HH}$-related protein kinases could also represent a suitable therapeutic approach for treating GLI-dependent tumors, especially those in which non-canonical activation of GLI limits the efficacy of SMOi (Montagnani and Stecca, 2019). For instance, pharmacological inhibition of DYRK1B has been reported to repress GLI expression downstream of SMO and subsequent in vivo tumor growth of both SMOi-sensitive and resistant pancreatic cancer cells (Gruber et al., 2016).

Bromodomain-containing protein 4 is another attractive therapeutic target for GLI-dependent tumors, since it has been directly involved in the transcriptional regulation of GLI. Of note, administration of the BET inhibitors JQ1 or I-BET-151 suppresses the $\mathrm{HH}$ pathway transcriptional output in several $\mathrm{HH}$-driven tumors, such as BCC, medulloblastoma and atypical teratoid rhabdoid tumors, even when the emergence of primary or acquired resistance mechanisms compromises the efficacy of SMO inhibitors (Long et al., 2014; Tang et al., 2014).

Targeting HDAC represents an additional intriguing therapeutic option, as members of HDAC have been reported to activate $\mathrm{HH}$ signaling by deacetylating GLI proteins. Indeed, the use of the selective HDAC1/2 inhibitor mocetinostat inhibits $\mathrm{HH}$ signaling and reduces tumor growth in preclinical models of SHH-dependent medulloblastoma (Coni et al., 2017). Further, the FDA-approved HDAC inhibitor vorinostat has been proposed in combination with small molecule inhibitors of aPKC for treating advanced BCC, since aPKC appears to mediate the recruitment of HDAC1 to GLI1 (Mirza et al., 2017). HDAC inhibitors have been also successfully used in combination with SMOi to improve the therapeutic outcome of several GLI-dependent tumors. For instance, co-administration of the HDAC inhibitor SAHA with vismodegib has been shown to suppress tumor growth in multiple aerodigestive cancer cell lines (Chun et al., 2015), and the dual HDAC/HH pathway inhibitor NL-103 effectively overcomes vismodegib resistance conferred 
by SMO-M2 and SMO-D473H mutants by downregulating the expression of GLI2 (Zhao et al., 2014). Of note, the small molecule HDAC inhibitor 4SC-202 displayed high efficacy in both vismodegib-sensitive and SUFU-depleted SMOi-resistant medulloblastoma cells, indicating that inhibition of HDAC activity could bypass the acquired resistance toward SMOi (Gruber et al., 2018).

\section{CONCLUSION}

A wealth of data indicate that the GLI transcription factors are regulated by several oncogenic signaling pathways and inputs in addition or independent of canonical PTCH-SMO signaling. These findings in part explain the failure of clinical trials with SMO antagonists, urging the development of novel therapeutic strategies to inhibit non-canonical HH signaling.

In general, canonical activation of HH-GLI signaling occurs in cancers with mutations in PTCH1 and SMO, such as BCC and SHH-type medulloblastoma, most of which are sensitive to SMO antagonists. As summarized in this review, several mechanisms of non-canonical activation of $\mathrm{HH}$ signaling in cancer have been reported (Table 1). In the majority of cancer types, including glioblastoma, melanoma, colon, prostate, esophageal and pancreatic cancers, one or more non-canonical $\mathrm{HH}$ signaling modes can take place. Thus, it is critical to understand specific, non-canonical mechanisms of $\mathrm{HH}$ pathway activation in a given tumor type before starting anti-cancer treatment. At this purpose, the development of in vitro and in vivo preclinical models, such as patient-derived cell lines, organoids and xenografts (PDX), will be needed to test the role of each aberrantly activated signaling pathway and provide personalized therapeutic options for individual patients. In addition, it will be equally important to establish sensitive and validated biomarkers of HH-GLI pathway activation, such as reliable antibodies against human GLI1 and GLI2 and their phosphorylated forms. For treatment involving SMO inhibitors (alone or in combination with other pathway inhibitors), a

\section{REFERENCES}

Abballe, L., Mastronuzzi, A., Miele, E., Carai, A., Besharat, Z. M., Moretti, M., et al. (2018). Numb isoforms deregulation in medulloblastoma and role of p66 isoform in cancer and neural stem cells. Front. Pediatr. 6:315. doi: 10.3389/fped. 2018.00315

Abe, Y., Suzuki, Y., Kawamura, K., and Tanaka, N. (2019). MEP50/PRMT5mediated methylation activates GLI1 in Hedgehog signalling through inhibition of ubiquitination by the ITCH/NUMB complex. Commun. Biol. 2:23. doi: 10 . 1038/s42003-018-0275-4

Aberger, F., Kern, D., Greil, R., and Hartmann, T. N. (2012). Canonical and noncanonical Hedgehog/GLI signaling in hematological malignancies. Vitam. Horm. 88, 25-54. doi: 10.1016/B978-0-12-394622-5.00002-X

Agarwal, N. K., Kim, C. H., Kunkalla, K., Konno, H., Tjendra, Y., Kwon, D., et al. (2016). Active IKK $\beta$ promotes the stability of GLI1 oncogene in diffuse large B-cell lymphoma. Blood 127, 605-615. doi: 10.1182/blood-2015-07-658781

Ahmad, A., Maitah, M. Y., Ginnebaugh, K. R., Li, Y., Bao, B., Gadgeel, S. M., et al. (2013). Inhibition of Hedgehog signaling sensitizes NSCLC cells to standard therapies through modulation of EMT-regulating miRNAs. J. Hematol. Oncol. 6:77. doi: $10.1186 / 1756-8722-6-77$ better biomarker for SMO activation should be developed, such as phospho-specific antibody to monitor SMO phosphorylation (Chen et al., 2011). The availability of such tools and biomarkers will allow to screen cancer patients and select those showing SMO and GLI activation, increasing the subset of cancer patients who will likely respond to $\mathrm{HH}-\mathrm{GLI}$ pathway inhibition and to monitor the efficacy of therapy.

In summary, both canonical $\mathrm{HH}$ signaling and the confluence of multiple SMO-independent oncogenic pathways can regulate the activity of the GLI transcription factors. Thus, a more effective therapeutic approach to fight cancers harboring non-canonical $\mathrm{HH}$ pathway activation would be to inhibit the GLI rather than SMO. Often in a given cancer type, canonical and non-canonical $\mathrm{HH}$ pathway activation co-exist. In some cancer types, more than one mechanism of non-canonical $\mathrm{HH}$ activation occurs simultaneously. Therefore, combined targeted therapy will be more effective than single treatment in blocking GLI-dependent tumor growth and progression.

\section{AUTHOR CONTRIBUTIONS}

SP and BS conceptualized the content, and reviewed and edited the manuscript. All authors wrote and approved the manuscript.

\section{FUNDING}

This research was supported by funding from Institute for Cancer Research, Prevention and Clinical Network (ISPRO) and a postdoctoral fellowship from Italian Association for Cancer Research to SP (AIRC, Project No. 21168).

\section{ACKNOWLEDGMENTS}

We thank Valentina Montagnani and Laura Carrassa for helpful comments on the manuscript.

Alexaki, V. I., Javelaud, D., Van Kempen, L. C., Mohammad, K. S., Dennler, S., Luciani, F., et al. (2010). GLI2-mediated melanoma invasion and metastasis. J. Natl. Cancer Inst. 102, 1148-1159. doi: 10.1093/jnci/djq257

Amakye, D., Jagani, Z., and Dorsch, M. (2013). Unraveling the therapeutic potential of the hedgehog pathway in cancer. Nat. Med. 19, 1410-1422. doi: 10.1038/nm. 3389

Antonucci, L., Di Magno, L., D’Amico, D., Manni, S., Serrao, S. M., Di Pastena, F., et al. (2019). Mitogen-activated kinase kinase kinase 1 inhibits hedgehog signaling and medulloblastoma growth through GLI1 phosphorylation. Int. J. Oncol. 54, 505-514. doi: 10.3892/ijo.2018.4638

Asaoka, Y., Kanai, F., Ichimura, T., Tateishi, K., Tanaka, Y., Ohta, M., et al. (2010). Identification of a suppressive mechanism for Hedgehog signaling through a novel interaction of Gli with 14-3-3. J. Biol. Chem. 285, 4185-4194. doi: 10.1074/ jbc.M109.038232

Atwood, S. X., Li, M., Lee, A., Tang, J. Y., and Oro, A. E. (2013). GLI activation by atypical protein kinase $\mathrm{Cl} / \lambda$ regulates the growth of basal cell carcinomas. Nature 494, 484-488. doi: 10.1038/nature11889

Atwood, S. X., Sarin, K. Y., Whitson, R. J., Li, J. R., Kim, G., Rezaee, M., et al. (2015). Smoothened variants explain the majority of drug resistance in basal cell carcinoma. Cancer Cell 27, 342-353. doi: 10.1016/j.ccell.2015.02.002 
Bannister, A. J., and Kouzarides, T. (2011). Regulation of chromatin by histone modifications. Cell Res. 21, 381-395. doi: 10.1038/cr.2011.22

Barakat, M. T., Humke, E. W., and Scott, M. P. (2010). Learning from jekyll to control hyde: hedgehog signaling in development and cancer. Trends Mol. Med. 16, 337-348. doi: 10.1016/j.molmed.2010.05.003

Bauer, N. C., Doetsch, P. W., and Corbett, A. H. (2015). Mechanisms regulating protein localization. Traffic 16, 1039-1061. doi: 10.1111/tra.12310

Beauchamp, E., Bulut, G., Abaan, O., Chen, K., Merchant, A., Matsui, W., et al. (2009). GLI1 is a direct transcriptional target of EWS-FLI1 oncoprotein. J. Biol. Chem. 284, 9074-9082. doi: 10.1074/jbc.M806233200

Beauchamp, E. M., Ringer, L., Bulut, G., Sajwan, K. P., Hall, M. D., Lee, Y. C., et al. (2011). Arsenic trioxide inhibits human cancer cell growth and tumor development in mice by blocking Hedgehog/GLI pathway. J. Clin. Invest. 121, 148-160. doi: 10.1172/JCI42874

Bieging, K. T., Mello, S. S., and Attardi, L. D. (2014). Unravelling mechanisms of p53-mediated tumour suppression. Nat. Rev. Cancer 14, 359-370. doi: 10.1038/ nrc3711

Bowles, D. W., Keysar, S. B., Eagles, J. R., Wang, G., Glogowska, M. J., McDermott, J. D., et al. (2016). A pilot study of cetuximab and the hedgehog inhibitor IPI-926 in recurrent/metastatic head and neck squamous cell carcinoma. Oral. Oncol. 53, 74-79. doi: 10.1016/j.oraloncology.2015.11.014

Brechbiel, J., Miller-Moslin, K., and Adjei, A. A. (2014). Crosstalk between hedgehog and other signaling pathways as a basis for combination therapies in cancer. Cancer Treat. Rev. 40, 750-759. doi: 10.1016/j.ctrv.2014.02.003

Buonamici, S., Williams, J., Morrissey, M., Wang, A., Guo, R., Vattay, A., et al. (2010). Interfering with resistance to smoothened antagonists by inhibition of the PI3K pathway in medulloblastoma. Sci. Transl. Med. 2:51ra70. doi: 10.1126/ scitranslmed.3001599

Cai, Q., Li, J., Gao, T., Xie, J., and Evers, B. M. (2009). Protein kinase Cdelta negatively regulates hedgehog signaling by inhibition of Gli1 activity. J. Biol. Chem. 284, 2150-2158. doi: 10.1074/jbc.M803235200

Cai, X., Yu, K., Zhang, L., Li, Y., Li, Q., Yang, Z., et al. (2015). Synergistic inhibition of colon carcinoma cell growth by Hedgehog-Gli1 inhibitor arsenic trioxide and phosphoinositide 3-kinase inhibitor LY294002. Onco. Targets Ther. 8, 877-883. doi: 10.2147/OTT.S71034

Canettieri, G., Di Marcotullio, L., Greco, A., Coni, S., Antonucci, L., Infante, P., et al. (2010). Histone deacetylase and Cullin3-REN(KCTD11) ubiquitin ligase interplay regulates hedgehog signalling through Gli acetylation. Nat. Cell Biol. 12, 132-142. doi: $10.1038 / \mathrm{ncb} 2013$

Cao, X., Geradts, J., Dewhirst, M. W., and Lo, H. W. (2012). Upregulation of VEGF$\mathrm{A}$ and CD24 gene expression by the tGLI1 transcription factor contributes to the aggressive behavior of breast cancer cells. Oncogene 31, 104-115. doi: 10.1038/onc.2011.219

Carpenter, R. L., and Lo, H. W. (2012). Hedgehog pathway and GLI1 isoforms in human cancer. Discov. Med. 13, 105-113.

Castellino, R. C., Barwick, B. G., Schniederjan, M., Buss, M. C., Becher, O., Hambardzumyan, D., et al. (2010). Heterozygosity for Pten promotes tumorigenesis in a mouse model of medulloblastoma. PLoS One 5:e10849. doi: 10.1371/journal.pone.0010849

Chen, S., Zhang, G., Yu, Q., Zhang, X., and Han, G. (2017). Mir-361 inhibited prostate carcinoma cell invasion by targeting GLI1. Int. J. Clin. Exp. Pathol. 10, 6108-6116.

Chen, Y., Sasai, N., Ma, G., Yue, T., Jia, J., Briscoe, J., et al. (2011). Sonic Hedgehog dependent phosphorylation by CK1alpha and GRK2 is required for ciliary accumulation and activation of Smoothened. PLoS Biol. 9:e1001083. doi: 10. 1371/journal.pbio.1001083

Cheng, Y., Lin, C. H., Chen, J. Y., Li, C. H., Liu, Y. T., and Chen, B. C. (2016). Induction of connective tissue growth factor expression by hypoxia in human lung fibroblasts via the MEKK1/MEK1/ERK1/GLI-1/GLI2 and AP-1 Pathways. PLoS One 11:e0160593. doi: 10.1371/journal.pone.01 60593

Chun, S. G., Park, H., Pandita, R. K., Horikoshi, N., Pandita, T. K., Schwartz, D. L., et al. (2015). Targeted inhibition of histone deacetylases and hedgehog signaling suppress tumor growth and homologous recombination in aerodigestive cancers. Am. J. Cancer Res. 5, 1337-1352.

Cochrane, C. R., Szczepny, A., Watkins, D. N., and Cain, J. E. (2015). Hedgehog signaling in the maintenance of cancer stem cells. Cancers 7, 1554-1585. doi: $10.3390 /$ cancers 7030851
Coni, S., Antonucci, L., D’Amico, D., Di Magno, L., Infante, P., De Smaele, E., et al. (2013). Gli2 acetylation at lysine 757 regulates hedgehog-dependent transcriptional output by preventing its promoter occupancy. PLoS One 8:e65718. doi: 10.1371/journal.pone.0065718

Coni, S., Mancuso, A. B., Di Magno, L., Sdruscia, G., Manni, S., Serrao, S. M., et al. (2017). Selective targeting of HDAC1/2 elicits anticancer effects through Gli1 acetylation in preclinical models of SHH Medulloblastoma. Sci. Rep. 7:44079. doi: 10.1038/srep44079

Corbit, K. C., Aanstad, P., Singla, V., Norman, A. R., Stainier, D. Y., and Reiter, J. F. (2005). Vertebrate Smoothened functions at the primary cilium. Nature 437, 1018-1021. doi: 10.1038/nature04117

Dai, P., Akimaru, H., Tanaka, Y., Maekawa, T., Nakafuku, M., and Ishii, S. (1999). Sonic Hedgehog-induced activation of the Glil promoter is mediated by GLI3. J. Biol. Chem. 274, 8143-8152. doi: 10.1074/jbc.274.12.8143

Dai, P., Shinagawa, T., Nomura, T., Harada, J., Kaul, S. C., Wadhwa, R., et al. (2002). Ski is involved in transcriptional regulation by the repressor and full-length forms of Gli3. Genes Dev. 16, 2843-2848. doi: 10.1101/gad.1017302

D’Amico, D., Antonucci, L., Di Magno, L., Coni, S., Sdruscia, G., Macone, A., et al. (2015). Non-canonical hedgehog/AMPK-mediated control of polyamine metabolism supports neuronal and medulloblastoma cell growth. Dev. Cell 35, 21-35. doi: 10.1016/j.devcel.2015.09.008

David, C. J., and Massagué, J. (2018). Contextual determinants of TGF $\beta$ action in development, immunity and cancer. Nat. Rev. Mol. Cell Biol. 19, 419-435. doi: 10.1038/s41580-018-0007-0

Denef, N., Neubüser, D., Perez, L., and Cohen, S. M. (2000). Hedgehog induces opposite changes in turnover and subcellular localization of patched and smoothened. Cell 102, 521-531. doi: 10.1016/S0092-8674(00)00056-8

Deng, W., Vanderbilt, D. B., Lin, C. C., Martin, K. H., Brundage, K. M., and Ruppert, J. M. (2015). SOX9 inhibits b-TrCP-mediated protein degradation to promote nuclear GLI1 expression and cancer stem cell properties. J. Cell Sci. 128, 1123-1138. doi: 10.1242/jcs. 162164

Dennler, S., André, J., Alexaki, I., Li, A., Magnaldo, T., ten Dijke, P., et al. (2007). Induction of sonic hedgehog mediators by transforming growth factor-beta: smad3-dependent activation of Gli2 and Gli1 expression in vitro and in vivo. Cancer Res. 67, 6981-6986. doi: 10.1158/0008-5472.CAN-07-0491

Dennler, S., André, J., Verrecchia, F., and Mauviel, A. (2009). Cloning of the human GLI2 promoter: transcriptional activation by transforming growth factor-beta via SMAD3/beta-catenin cooperation. J. Biol. Chem. 284, 31523-31531. doi: 10.1074/jbc.M109.059964

Dhanyamraju, P. K., Holz, P. S., Finkernagel, F., Fendrich, V., and Lauth, M. (2015). Histone deacetylase 6 represents a novel drug target in the oncogenic Hedgehog signaling pathway. Mol. Cancer Ther. 14, 727-739. doi: 10.1158/1535-7163. MCT-14-0481

Di Magno, L., Basile, A., Coni, S., Manni, S., Sdruscia, G., D’Amico, D., et al. (2016). The energy sensor AMPK regulates Hedgehog signaling in human cells through a unique Gli1 metabolic checkpoint. Oncotarget 7, 9538-9549. doi: 10.18632 /oncotarget.7070

Di Marcotullio, L., Ferretti, E., Greco, A., De Smaele, E., Po, A., Sico, M., et al. (2006). Numb is a suppressor of Hedgehog signalling and targets Gli1 for Itchdependent ubiquitination. Nat. Cell Biol. 8, 1415-1423. doi: 10.1038/ncb1510

Di Marcotullio, L., Greco, A., Mazza, D., Canettieri, G., Pietrosanti, L., Infante, P., et al. (2011). Numb activates the E3 ligase Itch to control Glil function through a novel degradation signal. Oncogene 30, 65-76. doi: 10.1038/onc.2010.394

Diao, Y., Rahman, M. F., Villegas, V. E., Wickström, M., Johnsen, J. I., and Zaphiropoulos, P. G. (2014). The impact of S6K1 kinase on neuroblastoma cell proliferation is independent of GLI1 signaling. BMC Cancer 14:600. doi: 10.1186/1471-2407-14-600

Dijkgraaf, G. J., Alicke, B., Weinmann, L., Januario, T., West, K., Modrusan, Z., et al. (2011). Small molecule inhibition of GDC-0449 refractory smoothened mutants and downstream mechanisms of drug resistance. Cancer Res. 71, 435-444. doi: 10.1158/0008-5472.CAN-10-2876

Doucette, T. A., Yang, Y., Pedone, C., Kim, J. Y., Dubuc, A., Northcott, P. D., et al. (2012). WIP1 enhances tumor formation in a sonic hedgehog-dependent model of medulloblastoma. Neurosurgery 70, 1003-1010. doi: 10.1227/NEU. 0b013e31823e5332

Dummer, R., Guminski, A., Gutzmer, R., Dirix, L., Lewis, K. D., Combemale, P., et al. (2016). The 12-month analysis from basal cell carcinoma outcomes with LDE225 treatment (BOLT): a phase II, randomized, double-blind study 
of sonidegib in patients with advanced basal cell carcinoma. J. Am. Acad. Dermatol. 75, 113-125. doi: 10.1016/j.jaad.2016.02.1226

Eberl, M., Klingler, S., Mangelberger, D., Loipetzberger, A., Damhofer, H., Zoidl, K., et al. (2012). Hedgehog-EGFR cooperation response genes determine the oncogenic phenotype of basal cell carcinoma and tumour-initiating pancreatic cancer cells. EMBO Mol. Med. 4, 218-233. doi: 10.1002/emmm.201100201

Ehe, B. K., Lamson, D. R., Tarpley, M., Onyenwoke, R. U., Graves, L. M., and Williams, K. P. (2017). Identification of a DYRK1A-mediated phosphorylation site within the nuclear localization sequence of the hedgehog transcription factor GLI1. Biochem. Biophys. Res. Commun. 491, 767-772. doi: 10.1016/j.bbrc. 2017.07.107

Eimer, S., Dugay, F., Airiau, K., Avril, T., Quillien, V., Belaud-Rotureau, M. A., et al. (2012). Cyclopamine cooperates with EGFR inhibition to deplete stemlike cancer cells in glioblastoma-derived spheroid cultures. Neuro. Oncol. 14, 1441-1451. doi: 10.1093/neuonc/nos266

Elsawa, S. F., Almada, L. L., Ziesmer, S. C., Novak, A. J., Witzig, T. E., Ansell, S. M., et al. (2011). GLI2 transcription factor mediates cytokine cross-talk in the tumor microenvironment. J. Biol. Chem. 286, 21524-21534. doi: 10.1074/ jbc.M111.234146

Fan, Q., He, M., Sheng, T., Zhang, X., Sinha, M., Luxon, B., et al. (2010). Requirement of TGFbeta signaling for SMO-mediated carcinogenesis. J. Biol. Chem. 285, 36570-36576. doi: 10.1074/jbc.C110.164442

Ferretti, E., De Smaele, E., Miele, E., Laneve, P., Po, A., Pelloni, M., et al. (2008). Concerted microRNA control of Hedgehog signalling in cerebellar neuronal progenitor and tumour cells. EMBO J. 27, 2616-2627. doi: 10.1038/emboj. 2008.172

Geng, Y., Liu, J., Xie, Y., Jiang, H., Zuo, K., Li, T., et al. (2018). Trichostatin A promotes GLI1 degradation and P21 expression in multiple myeloma cells. Cancer Manag. Res. 10, 2905-2914. doi: 10.2147/CMAR.S167330

Gioeli, D., Wunderlich, W., Sebolt-Leopold, J., Bekiranov, S., Wulfkuhle, J. D., Petricoin, E. F. III, et al. (2011). Compensatory pathways induced by MEK inhibition are effective drug targets for combination therapy against castrationresistant prostate cancer. Mol. Cancer Ther. 10, 1581-1590. doi: 10.1158/15357163.MCT-10-1033

Goetz, S. C., and Anderson, K. V. (2010). The primary cilium: a signalling centre during vertebrate development. Nat. Rev. Genet. 11, 331-344. doi: 10.1038/ $\operatorname{nrg} 2774$

Götschel, F., Berg, D., Gruber, W., Bender, C., Eberl, M., Friedel, M., et al. (2013). Synergism between Hedgehog-GLI and EGFR signaling in Hedgehogresponsive human medulloblastoma cells induces downregulation of canonical Hedgehog-target genes and stabilized expression of GLI1. PLoS One 8:e65403. doi: 10.1371/journal.pone.0065403

Grachtchouk, M., Pero, J., Yang, S. H., Ermilov, A. N., Michael, L. E., Wang, A., et al. (2011). Basal cell carcinomas in mice arise from hair follicle stem cells and multiple epithelial progenitor populations. J. Clin. Invest. 121, 1768-1781. doi: 10.1172/JCI46307

Gruber, W., Hutzinger, M., Elmer, D. P., Parigger, T., Sternberg, C., Cegielkowski, L., et al. (2016). DYRK1B as therapeutic target in Hedgehog/GLI-dependent cancer cells with Smoothened inhibitor resistance. Oncotarget 7, 7134-7148. doi: 10.18632/oncotarget.6910

Gruber, W., Peer, E., Elmer, D. P., Sternberg, C., Tesanovic, S., Del Burgo, P., et al. (2018). Targeting class I histone deacetylases by the novel small molecule inhibitor 4SC-202 blocks oncogenic hedgehog-GLI signaling and overcomes smoothened inhibitor resistance. Int. J. Cancer 142, 968-975. doi: 10.1002/ijc. 31117

Gruber-Filbin, M., Dabral, S. K., Pazyra-Murphy, M. F., Ramkissoon, S., Kung, A. L., Pak, E., et al. (2013). Coordinate activation of Shh and PI3K signaling in PTEN-deficient glioblastoma: new therapeutic opportunities. Nat. Med. 19, 1518-1523. doi: $10.1038 / \mathrm{nm} .3328$

Gulino, A., Di Marcotullio, L., and Screpanti, I. (2010). The multiple functions of numb. Exp. Cell Res. 316, 900-906. doi: 10.1016/j.yexcr.2009.11.017

Gupta, S., Takebe, N., and Lorusso, P. (2010). Targeting the Hedgehog pathway in cancer. Ther. Adv. Med. Oncol. 2, 237-250. doi: 10.1177/1758834010366430

Gurung, B., Feng, Z., and Hua, X. (2013). Menin directly represses Gli1 expression independent of canonical Hedgehog signaling. Mol. Cancer Res. 11, 1215-1222. doi: 10.1158/1541-7786.MCR-13-0170

Han, B. C., Qu, Y., Jin, Y. L., Yu, Y., Deng, N., Wawrowsky, K., et al. (2015). FOXC1 activates smoothened-independent hedgehog signaling in basal-like breast cancer. Cell Rep. 13, 1046-1058. doi: 10.1016/j.celrep.2015. 09.063

Han, Y., Shi, Q., and Jiang, J. (2015). Multisite interaction with Sufu regulates Ci/Gli activity through distinct mechanisms in Hh signal transduction. Proc. Natl. Acad. Sci. U.S.A. 112, 6383-6388. doi: 10.1073/pnas.1421628112

Han, Y., Xiong, Y., Shi, X., Wu, J., Zhao, Y., and Jiang, J. (2017). Regulation of Gli ciliary localization and Hedgehog signaling by the PY-NLS/karyopherin$\beta 2$ nuclear import system. PLoS Biol. 15:e2002063. doi: 10.1371/journal.pbio. 2002063

Hanna, A., and Shevde, L. A. (2016). Hedgehog signaling: modulation of cancer properies and tumor mircroenvironment. Mol. Cancer 15:24. doi: 10.1186/ s12943-016-0509-3

Hoch, L., Faure, H., Roudaut, H., Schoenfelder, A., Mann, A., Girard, N., et al. (2015). MRT-92 inhibits Hedgehog signaling by blocking overlapping binding sites in the transmembrane domain of the Smoothened receptor. FASEB J. 29, 1817-1829. doi: 10.1096/fj.14-267849

Huang, Y., Nahar, S., Nakagawa, A., Fernandez-Barrena, M. G., Mertz, J. A., Bryant, B. M., et al. (2016). Regulation of GLI underlies a Role for BET bromodomains in pancreatic cancer growth and the tumor microenvironment. Clin. Cancer Res. 22, 4259-4270. doi: 10.1158/1078-0432.CCR-15-2068

Huntzicker, E. G., Estay, I. S., Zhen, H., Lokteva, L. A., Jackson, P. K., and Oro, A. E. (2006). Dual degradation signals control Gli protein stability and tumor formation. Genes Dev. 20, 276-281. doi: 10.1101/gad.1380906

Hyman, J. M., Firestone, A. J., Heine, V. M., Zhao, Y., Ocasio, C. A., Han, K., et al. (2009). Small-molecule inhibitors reveal multiple strategies for Hedgehog pathway blockade. Proc. Natl. Acad. Sci. U.S.A. 106, 14132-14137. doi: 10.1073/ pnas.0907134106

Ikram, M. S., Neill, G. W., Regl, G., Eichberger, T., Frischauf, A. M., Aberger, F., et al. (2004). GLI2 is expressed in normal human epidermis and BCC and induces GLI1 expression by binding to its promoter. J. Invest. Dermatol. 122, 1503-1509. doi: 10.1111/j.0022-202X.2004.22612.x

Infante, P., Mori, M., Alfonsi, R., Ghirga, F., Aiello, F., Toscano, S., et al. (2015). Gli1/DNA interaction is a druggable target for Hedgehog-dependent tumors. EMBO J. 34, 200-217. doi: 10.15252/embj.201489213

Ingham, P. W., and McMahon, A. P. (2001). Hedgehog signaling in animal development: paradigms and principles. Genes Dev. 15, 3059-3087. doi: 10. 1101/gad.938601

Iwasaki, H., Nakano, K., Shinkai, K., Kunisawa, Y., Hirahashi, M., Oda, Y., et al. (2013). Hedgehog Gli3 activator signal augments tumorigenicity of colorectal cancer via upregulation of adherence-related genes. Cancer Sci. 104, 328-336. doi: $10.1111 /$ cas. 12073

Jagani, Z., Mora-Blanco, E. L., Sansam, C. G., McKenna, E. S., Wilson, B., Chen, D., et al. (2010). Loss of the tumor suppressor Snf5 leads to aberrant activation of the Hedgehog-Gli pathway. Nat. Med. 16, 1429-1433. doi: 10.1038/nm.2251

Ji, Z., Mei, F. C., Xie, J., and Cheng, X. (2007). Oncogenic KRAS activates hedgehog signaling pathway in pancreatic cancer cells. J. Biol. Chem. 282, 14048-14055. doi: 10.1074/jbc.M611089200

Jiang, Z., Cushing, L., Ai, X., and Lü, J. (2014). miR-326 is downstream of Sonic hedgehog signaling and regulates the expression of Gli2 and smoothened. Am. J. Respir. Cell Mol. Biol. 51, 273-283. doi: 10.1165/rcmb.2013-0127OC

Jinawath, A., Akiyama, Y., Sripa, B., and Yuasa, Y. (2007). Dual blockade of the hedgehog and ERK1/2 pathways coordinately decreases proliferation and survival of cholangiocarcinoma cells. J. Cancer Res. Clin. Oncol. 133, 271-278. doi: 10.1007/s00432-006-0166-9

Johnson, R. W., Nguyen, M. P., Padalecki, S. S., Grubbs, B. G., Merkel, A. R., Oyajobi, B. O., et al. (2011). TGF-beta promotion of Gli2-induced expression of parathyroid hormone-related protein, an important osteolytic factor in bone metastasis, is independent of canonical Hedgehog signaling. Cancer Res. 71, 822-831. doi: 10.1158/0008-5472.CAN-10-2993

Joo, J., Christensen, L., Warner, K., States, L., Kang, H. G., Vo, K., et al. (2009). GLI1 is a central mediator of EWS/FLI1 signaling in Ewing tumors. PLoS One 4:e7608. doi: 10.1371/journal.pone.0007608

Justilien, V., Walsh, M. P., Ali, S. A., Thompson, E. A., Murray, N. R., and Fields, A. P. (2014). The PRKC 1 and SOX2 oncogenes are coamplified and cooperate to activate Hedgehog signaling in lung squamous cell carcinoma. Cancer Cell 25, 139-151. doi: 10.1016/j.ccr.2014.01.008

Kasiri, S., Shao, C., Chen, B., Wilson, A. N., Yenerall, P., Timmons, B. C., et al. (2017). GLI1 blockade potentiates the antitumor activity of PI3K antagonists in 
lung squamous cell carcinoma. Cancer Res. 77, 4448-4459. doi: 10.1158/00085472.CAN-16-3315

Kasper, M., Schnidar, H., Neill, G. W., Hanneder, M., Klingler, S., Blaas, L., et al. (2006). Selective modulation of Hedgehog/GLI target gene expression by epidermal growth factor signaling in human keratinocytes. Mol. Cell Biol. 26, 6283-6298. doi: 10.1128/MCB.02317-05

Katoh, Y., and Katoh, M. (2009). Hedgehog target genes: mechanisms of carcinogenesis induced by aberrant hedgehog signaling activation. Curr. Mol. Med. 9, 873-886. doi: 10.2174/156652409789105570

Kebenko, M., Drenckhan, A., Gros, S. J., Jücker, M., Grabinski, N., Ewald, F., et al. (2015). ErbB2 signaling activates the Hedgehog pathway via PI3KAkt in human esophageal adenocarcinoma: identification of novel targets for concerted therapy concepts. Cell Signal. 27, 373-381. doi: 10.1016/j.cellsig.2014. 11.022

Kim, J., Lee, J. J., Kim, J., Gardner, D., and Beachy, P. A. (2010). Arsenic antagonizes the Hedgehog pathway by preventing ciliary accumulation and reducing stability of the Gli2 transcriptional effector. Proc. Natl. Acad. Sci. U.S.A. 107, 13432-13437. doi: 10.1073/pnas. 1006822107

Kinzler, K. W., Hamilton, S. R., and Vogelstein, B. (1987). Increased expression of the epidermal growth factor receptor gene in malignant gliomas is invariably associated with gene amplification. Proc. Natl. Acad. Sci. U.S.A. 84, 6899-6903. doi: 10.1073/pnas.84.19.6899

Kinzler, K. W., and Vogelstein, B. (1990). The GLI gene encodes a nuclear protein which binds specific sequences in the human genome. Mol. Cell. Biol. 10, 634-642. doi: 10.1128/mcb.10.2.634

Kogerman, P., Grimm, T., Kogerman, L., Krause, D., Undén, A. B., Sandstedt, B., et al. (1999). Mammalian suppressor-of-fused modulates nuclear-cytoplasmic shuttling of Gli-1. Nat. Cell Biol. 1, 312-319. doi: 10.1038/13031

Kovacs, J. J., Whalen, E. J., Liu, R., Xiao, K., Kim, J., Chen, M., et al. (2008). Betaarrestin-mediated localization of smoothened to the primary cilium. Science 320, 1777-1781. doi: 10.1126/science.1157983

Lauth, M., Bergström, A., Shimokawa, T., and Toftgård, R. (2007). Inhibition of GLI-mediated transcription and tumor cell growth by small-molecule antagonists. Proc. Natl. Acad. Sci. U.S.A. 104, 8455-8460. doi: 10.1073/pnas. 0609699104

Lauth, M., Bergström, A., Shimokawa, T., Tostar, U., Jin, Q., Fendrich, V., et al. (2010). DYRK1B-dependent autocrine-to-paracrine shift of Hedgehog signaling by mutant RAS. Nat. Struct. Mol. Biol. 17, 718-725. doi: 10.1038/ nsmb. 1833

Li, N., Truong, S., Nouri, M., Moore, J., Al Nakouzi, N., Lubik, A. A., et al. (2018). Non-canonical activation of hedgehog in prostate cancer cells mediated by the interaction of transcriptionally active androgen receptor proteins with Gli3. Oncogene 37, 2313-2325. doi: 10.1038/s41388-017-0098-7

Li, Y. H., Luo, J., Mosley, Y. Y., Hedrick, V. E., Paul, L. N., Chang, J., et al. (2015). AMP-Activated protein kinase directly phosphorylates and destabilizes hedgehog pathway transcription factor GLI1 in medulloblastoma. Cell Rep. 12, 599-609. doi: 10.1016/j.celrep.2015.06.054

Ling, H., Fabbri, M., and Calin, G. A. (2013). MicroRNAs and other non-coding RNAs as targets for anticancer drug development. Nat. Rev. Drug Discov. 12, 847-865. doi: 10.1038/nrd4140

Liu, Z., Li, T., Reinhold, M. I., and Naski, M. C. (2014). MEK1-RSK2 contributes to Hedgehog signaling by stabilizing GLI2 transcription factor and inhibiting ubiquitination. Oncogene 33, 65-73. doi: 10.1038/onc.2012.544

Lo, H. W., Zhu, H., Cao, X., Aldrich, A., and Ali-Osman, F. (2009). A novel splice variant of GLI1 that promotes glioblastoma cell migration and invasion. Cancer Res. 69, 6790-6798. doi: 10.1158/0008-5472.CAN-09-0886

Long, J., Li, B., Rodriguez-Blanco, J., Pastori, C., Volmar, C. H., Wahlestedt, C., et al. (2014). The BET bromodomain inhibitor I-BET151 acts downstream of smoothened protein to abrogate the growth of hedgehog proteindriven cancers. J. Biol. Chem. 289, 35494-35502. doi: 10.1074/jbc.M114. 595348

LoRusso, P. M., Rudin, C. M., Reddy, J. C., Tibes, R., Weiss, G. J., Borad, M. J., et al. (2011). Phase I trial of hedgehog pathway inhibitor vismodegib (GDC-0449) in patients with refractory, locally advanced or metastatic solid tumors. Clin. Cancer Res. 17, 2502-2511. doi: 10.1158/1078-0432.CCR-10-2745

Lu, J., Liu, L., Zheng, M., Li, X., Wu, A., Wu, Q., et al. (2018). MEKK2 and MEKK3 suppress Hedgehog pathway-dependent medulloblastoma by inhibiting GLI1 function. Oncogene 37, 3864-3878. doi: 10.1038/s41388-018-0249-5
Malatesta, M., Steinhauer, C., Mohammad, F., Pandey, D. P., Squatrito, M., and Helin, K. (2013). Histone acetyltransferase PCAF is required for HedgehogGli-dependent transcription and cancer cell proliferation. Cancer Res. 73, 6323-6333. doi: 10.1158/0008-5472.CAN-12-4660

Mao, J., Maye, P., Kogerman, P., Tejedor, F. J., Toftgard, R., Xie, W., et al. (2002). Regulation of Gli1 transcriptional activity in the nucleus by Dyrk1. J. Biol. Chem. 277, 35156-35161. doi: 10.1074/jbc.M206743200

Martinelli, G., Oehler, V. G., Papayannidis, C., Courtney, R., Shaik, M. N., Zhang, X., et al. (2015). Treatment with PF-04449913, an oral smoothened antagonist, in patients with myeloid malignancies: A phase 1 safety and pharmacokinetics study. Lancet Haematol. 2, e339-e346. doi: 10.1016/S2352-3026(15)00096- 4

Mastrangelo, E., and Milani, M. (2018). Role and inhibition of GLI1 protein in cancer. Lung Cancer 27, 35-43. doi: 10.2147/LCTT.S124483

Mazumdar, T., DeVecchio, J., Agyeman, A., Shi, T., and Houghton, J. A. (2011). The GLI genes as the molecular switch in disrupting Hedgehog signaling in colon cancer. Oncotarget 2, 638-645. doi: 10.18632/oncotarget.310

Mazzà, D., Infante, P., Colicchia, V., Greco, A., Alfonsi, R., Siler, M., et al. (2013). PCAF ubiquitin ligase activity inhibits Hedgehog/Glil signaling in p53dependent response to genotoxic stress. Cell Death Differ. 20, 1688-1697. doi: $10.1038 /$ cdd. 2013.120

Miele, E., Po, A., Begalli, F., Antonucci, L., Mastronuzzi, A., Marras, C. E., et al. (2017). $\beta$-arrestin1-mediated acetylation of Glil regulates Hedgehog/Gli signaling and modulates self-renewal of $\mathrm{SHH}$ medulloblastoma cancer stem cells. BMC Cancer 17:488. doi: 10.1186/s12885-017-3477-0

Mimeault, M., Johansson, S. L., Vankatraman, G., Moore, E., Henichart, J. P., Depreux, P., et al. (2007). Combined targeting of epidermal growth factor receptor and hedgehog signaling by gefitinib and cyclopamine cooperatively improves the cytotoxic effects of docetaxel on metastatic prostate cancer cells. Mol. Cancer Ther. 6, 967-978. doi: 10.1158/1535-7163.MCT-06-0648

Mimeault, M., Moore, E., Moniaux, N., Henichart, J. P., Depreux, P., Lin, M. F., et al. (2006). Cytotoxic effects induced by a combination of cyclopamine and gefitinib, the selective hedgehog and epidermal growth factor receptor signaling inhibitors, in prostate cancer cells. Int. J. Cancer 118, 1022-1031. doi: 10.1002/ ijc. 21440

Mirza, A. N., Fry, M. A., Urman, N. M., Atwood, S. X., Roffey, J., Ott, G. R., et al. (2017). Combined inhibition of atypical PKC and histone deacetylase 1 is cooperative in basal cell carcinoma treatment. JCI Insight 2:97071. doi: 10.1172/jci.insight.97071

Miyazaki, Y., Matsubara, S., Ding, Q., Tsukasa, K., Yoshimitsu, M., Kosai, K., et al. (2016). Efficient elimination of pancreatic cancer stem cells by hedgehog/GLI inhibitor GANT61 in combination with mTOR inhibition. Mol. Cancer 15:49. doi: 10.1186/s12943-016-0534-2

Mizuarai, S., Kawagishi, A., and Kotani, H. (2009). Inhibition of p70S6K2 downregulates Hedgehog/GLI pathway in non-small cell lung cancer cell lines. Mol. Cancer 8:44. doi: 10.1186/1476-4598-8-44

Montagnani, V., and Stecca, B. (2019). Role of protein kinases in hedgehog pathway control and implications for cancer therapy. Cancers 11:E449. doi: 10.3390/ cancers 11040449

Morton, J. P., Mongeau, M. E., Klimstra, D. S., Morris, J. P., Lee, Y. C., Kawaguchi, Y., et al. (2007). Sonic hedgehog acts at multiple stages during pancreatic tumorigenesis. Proc. Natl. Acad. Sci. U.S.A. 104, 5103-5108. doi: 10.1073/pnas. 0701158104

Mujtaba, S., Zeng, L., and Zhou, M. M. (2007). Structure and acetyl-lysine recognition of the bromodomain. Oncogene 26, 5521-5527. doi: 10.1038/sj.onc. 1210618

Neill, G. W., Ghali, L. R., Green, J. L., Ikram, M. S., Philpott, M. P., and Quinn, A. G. (2003). Loss of protein kinase Calpha expression may enhance the tumorigenic potential of Gli1 in basal cell carcinoma. Cancer Res. 63, 4692-4697.

Niewiadomski, P., Kong, J. H., Ahrends, R., Ma, Y., Humke, E. W., Khan, S., et al. (2014). Gli protein activity is controlled by multisite phosphorylation in vertebrate Hedgehog signaling. Cell Rep. 6, 168-181. doi: 10.1016/j.celrep.2013. 12.003

Nolan-Stevaux, O., Lau, J., Truitt, M. L., Chu, G. C., Hebrok, M., FernándezZapico, M. E., et al. (2009). GLI1 is regulated through Smoothened-independent mechanisms in neoplastic pancreatic ducts and mediates PDAC cell survival and transformation. Genes Dev. 23, 24-36. doi: 10.1101/gad.1753809

Nye, M. D., Almada, L. L., Fernandez-Barrena, M. G., Marks, D. L., Elsawa, S. F., Vrabel, A., et al. (2014). The transcription factor GLI1 interacts 
with SMAD proteins to modulate transforming growth factor $\beta$-induced gene expression in a p300/CREB-binding protein-associated factor (PCAF)dependent manner. J. Biol. Chem. 289, 15495-15506. doi: 10.1074/jbc.M113.54 5194

Oliveto, S., Mancino, M., Manfrini, N., and Biffo, S. (2017). Role of microRNAs in translation regulation and cancer. World J. Biol. Chem. 8, 45-56. doi: 10.4331/ wjbc.v8.i1.45

Palle, K., Mani, C., Tripathi, K., and Athar, M. (2015). Aberrant GLI1 activation in DNA damage response, carcinogenesis and chemoresistance. Cancers 7 , 2330-2351. doi: 10.3390/cancers7040894

Palma, V., Lim, D. A., Dahmane, N., Sanchez, P., Brionne, T. C., Herzberg, C. D., et al. (2005). Sonic hedgehog controls stem cell behavior in the postnatal and adult brain. Development 132, 335-344. doi: 10.1242/dev.01567

Palma, V., and Ruiz i Altaba, A. (2004). Hedgehog-GLI signaling regulates the behavior of cells with stem cell properties in the developing neocortex. Development 131, 337-345. doi: 10.1242/dev.00930

Pan, Y., Bai, C. B., Joyner, A. L., and Wang, B. (2006). Sonic hedgehog signaling regulates Gli2 transcriptional activity by suppressing its processing and degradation. Mol. Cell. Biol. 26, 3365-3377. doi: 10.1128/MCB.26.9.33653377.2006

Pan, Y., and Wang, B. (2007). A novel protein-processing domain in Gli2 and Gli3 differentially blocks complete protein degradation by the proteasome. J. Biol. Chem. 282, 10846-10852. doi: 10.1074/jbc.M608599200

Pandolfi, S., Montagnani, V., Penachioni, J. Y., Vinci, M. C., Olivito, B., Borgognoni, L., et al. (2013). WIP1 phosphatase modulates the Hedgehog signaling by enhancing GLI1 function. Oncogene 32, 4737-4747. doi: 10.1038/ onc.2012.502

Pantazi, E., Gemenetzidis, E., Trigiante, G., Warnes, G., Shan, L., Mao, X., et al. (2014). GLI2 induces genomic instability in human keratinocytes by inhibiting apoptosis. Cell Death Dis. 5:e1028. doi: 10.1038/cddis.2013.535

Pasca di Magliano, M., Sekine, S., Ermilov, A., Ferris, J., Dlugosz, A. A., and Hebrok, M. (2006). Hedgehog/Ras interactions regulate early stages of pancreatic cancer. Genes Dev. 20, 3161-3173. doi: 10.1101/gad.1470806

Paul, P., Volny, N., Lee, S., Qiao, J., and Chung, D. H. (2013). Gli1 transcriptional activity is negatively regulated by AKT2 in neuroblastoma. Oncotarget 4, 1149-1157. doi: 10.18632/oncotarget.1074

Pavletich, N. P., and Pabo, C. O. (1993). Crystal structure of a five-finger GLIDNA complex: new perspectives on zinc fingers. Science 261, 1701-1707. doi: $10.1126 /$ science. 8378770

Peterson, K. A., Nishi, Y., Ma, W., Vedenko, A., Shokri, L., Zhang, X., et al. (2012). Neural-specific Sox2 input and differential Gli-binding affinity provide context and positional information in Shh-directed neural patterning. Genes Dev. 26, 2802-2816. doi: 10.1101/gad.207142.112

Pietanza, M. C., Litvak, A. M., Varghese, A. M., Krug, L. M., Fleisher, M., Teitcher, J. B., et al. (2016). A phase I trial of the Hedgehog inhibitor, sonidegib (LDE225), in combination with etoposide and cisplatin for the initial treatment of extensive stage small cell lung cancer. Lung Cancer 99, 23-30. doi: 10.1016/j. lungcan.2016.04.014

Pietrobono, S., Santini, R., Gagliardi, S., Dapporto, F., Colecchia, D., Chiariello, M., et al. (2018). Targeted inhibition of Hedgehog-GLI signaling by novel acylguanidine derivatives inhibits melanoma cell growth by inducing replication stress and mitotic catastrophe. Cell Death Dis. 9:142. doi: 10.1038/ s41419-017-0142-0

Pietrobono, S., and Stecca, B. (2018). Targeting the oncoprotein smoothened by small molecules: focus on novel acylguanidine derivatives as potent smoothened inhibitors. Cells 7:E272. doi: 10.3390/cells7120272

Po, A., Silvano, M., Miele, E., Capalbo, C., Eramo, A., Salvati, V., et al. (2017). Noncanonical GLI1 signaling promotes stemness features and in vivo growth in lung adenocarcinoma. Oncogene 36, 4641-4652. doi: 10.1038/onc. 2017.91

Pricl, S., Cortelazzi, B., Dal Col, V., Marson, D., Laurini, E., Fermeglia, M., et al. (2015). Smoothened (SMO) receptor mutations dictate resistance to vismodegib in basal cell carcinoma. Mol. Oncol. 9, 389-397. doi: 10.1016/j. molonc.2014.09.003

Regl, G., Kasper, M., Schnidar, H., Eichberger, T., Neill, G. W., Philpott, M. P., et al. (2004). Activation of the BCL2 promoter in response to Hedgehog/GLI signal transduction is predominantly mediated by GLI2. Cancer Res. 64, 7724-7731. doi: 10.1158/0008-5472.CAN-04-1085
Riobò, N. A., Haines, G. M., and Emerson, C. P. Jr. (2006a). Protein kinase C-delta and mitogen-activated protein/extracellular signal-regulated kinase- 1 control GLI activation in hedgehog signaling. Cancer Res. 66, 839-845. doi: 10.1158/ 0008-5472.CAN-05-2539

Riobò, N. A., Lu, K., Ai, X., Haines, G. M., and Emerson, C. P. Jr. (2006b). Phosphoinositide 3-kinase and Akt are essential for Sonic Hedgehog signaling. Proc. Natl. Acad. Sci. U.S.A. 103, 4505-4510. doi: 10.1073/pnas.0504337103

Rodon, J., Tawbi, H. A., Thomas, A. L., Stoller, R. G., Turtschi, C. P., Baselga, J., et al. (2014). A phase I, multicenter, open-label, first-in-human, dose-escalation study of the oral smoothened inhibitor Sonidegib (LDE225) in patients with advanced solid tumors. Clin. Cancer Res. 20, 1900-1909. doi: 10.1158/10780432.CCR-13-1710

Roessler, E., Ermilov, A. N., Grange, D. K., Wang, A., Grachtchouk, M., Dlugosz, A. A., et al. (2005). A previously unidentified amino-terminal domain regulates transcriptional activity of wild-type and disease-associated human GLI2. Hum. Mol. Genet. 14, 2181-2188. doi: 10.1093/hmg/ddi222

Rohatgi, R., Milenkovic, L., and Scott, M. P. (2007). Patched1 regulates hedgehog signaling at the primary cilium. Science $317,372-376$. doi: 10.1126/science. 1139740

Rovida, E., and Stecca, B. (2015). Mitogen-activated protein kinases and HedgehogGLI signaling in cancer: a crosstalk providing therapeutic opportunities? Semin. Cancer Biol. 35, 154-167. doi: 10.1016/j.semcancer.2015.08.003

Sadam, H., Liivas, U., Kazantseva, A., Pruunsild, P., Kazantseva, J., Timmusk, T., et al. (2016). GLI2 cell-specific activity is controlled at the level of transcription and RNA processing: consequences to cancer metastasis. Biochim. Biophys. Acta 1862, 46-55. doi: 10.1016/j.bbadis.2015.10.008

Samatar, A. A., and Poulikakos, P. I. (2014). Targeting RAS-ERK signalling in cancer: promises and challenges. Nat. Rev. Drug Discov. 13, 928-942. doi: 10. 1038/nrd4281

Savona, M. R., Pollyea, D. A., Stock, W., Oehler, V. G., Schroeder, M. A., Lancet, J., et al. (2018). Phase Ib study of glasdegib, a hedgehog pathway inhibitor, in combination with standard chemotherapy in patients with AML or High-Risk MDS. Clin. Cancer Res. 24, 2294-2303. doi: 10.1158/1078-0432.CCR-17-2824

Schneider, P., Bayo-Fina, J. M., Singh, R., Dhanyamraju, P. K., Holz, P., Baier, A., et al. (2015). Identification of a novel actin-dependent signal transducing module allows for the targeted degradation of GLI1. Nat. Commun. 6:8023. doi: $10.1038 /$ ncomms 9023

Schnidar, H., Eberl, M., Klingler, S., Mangelberger, D., Kasper, M., HauserKronberger, C., et al. (2009). Epidermal growth factor receptor signaling synergizes with Hedgehog/GLI in oncogenic transformation via activation of the MEK/ERK/JUN pathway. Cancer Res. 69, 1284-1292. doi: 10.1158/00085472.CAN-08-2331

Sekulic, A., Migden, M. R., Oro, A. E., Dirix, L., Lewis, K. D., Hainsworth, J. D., et al. (2012). Efficacy and safety of vismodegib in advanced basal-cell carcinoma. N. Engl. J. Med. 366, 2171-2179. doi: 10.1056/NEJMoa1113713

Seto, M., Ohta, M., Asaoka, Y., Ikenoue, T., Tada, M., Miyabayashi, K., et al. (2009). Regulation of the hedgehog signaling by the mitogen-activated protein kinase cascade in gastric cancer. Mol. Carcinog. 48, 703-712. doi: 10.1002/mc.20516

Sharma, N., Nanta, R., Sharma, J., Gunewardena, S., Singh, K. P., Shankar, S., et al. (2015). PI3K/AKT/mTOR and sonic hedgehog pathways cooperate together to inhibit human pancreatic cancer stem cell characteristics and tumor growth. Oncotarget 6, 32039-32060. doi: 10.18632/oncotarget.5055

Sharpe, H. J., Pau, G., Dijkgraaf, G. J., Basset-Seguin, N., Modrusan, Z., Januario, T., et al. (2015). Genomic analysis of smoothened inhibitor resistance in basal cell carcinoma. Cancer Cell 27, 327-341. doi: 10.1016/j.ccell.2015.02.001

Shimokawa, T., Tostar, U., Lauth, M., Palaniswamy, R., Kasper, M., Toftgard, R., et al. (2008). Novel human glioma-associated oncogene 1 (GLI1) splice variants reveal distinct mechanisms in the terminal transduction of the hedgehog signal. J. Biol. Chem. 283, 14345-14354. doi: 10.1074/jbc.M800299200

Singh, R., Dhanyamraju, P. K., and Lauth, M. (2017). DYRK1B blocks canonical and promotes non-canonical hedgehog signaling through activation of the mTOR/AKT pathway. Oncotarget 8, 833-845. doi: 10.18632/oncotarget.13662

Singh, R. R., Cho-Vega, J. H., Davuluri, Y., Ma, S., Kasbidi, F., Milito, C., et al. (2009). Sonic hedgehog signaling pathway is activated in ALK-positive anaplastic large cell lymphoma. Cancer Res. 69, 2550-2558. doi: 10.1158/00085472.CAN-08-1808

Speek, M., Njunkova, O., Pata, I., Valdre, E., and Kogerman, P. (2006). A potential role of alternative splicing in the regulation of the transcriptional activity of 
human GLI2 in gonadal tissues. BMC Mol. Biol. 7:13. doi: 10.1186/1471-21997-13

Stathis, A., Hess, D., von Moos, R., Homicsko, K., Griguolo, G., Joerger, M., et al. (2017). Swiss Group for Clinical Cancer Research (SAKK). Phase I trial of the oral smoothened inhibitor sonidegib in combination with paclitaxel in patients with advanced solid tumors. Investig. New Drugs 35, 766-772. doi: 10.1007/ s10637-017-0454-z

Stecca, B., Mas, C., Clement, V., Zbinden, M., Correa, R., Piguet, V., et al. (2007). Melanomas require HEDGEHOG-GLI signaling regulated by interactions between GLI1 and the RAS-MEK/AKT pathways. Proc. Natl. Acad. Sci. U.S.A. 104, 5895-5900. doi: 10.1073/pnas.0700776104

Stecca, B., and Ruiz i Altaba, A. (2009). A GLI1-p53 inhibitory loop controls neural stem cell and tumour cell numbers. EMBO J. 28, 663-676. doi: 10.1038/emboj. 2009.16

Steg, A. D., Bevis, K. S., Katre, A. A., Ziebarth, A., Dobbin, Z. C., Alvarez, R. D., et al. (2012). Stem cell pathways contribute to clinical chemoresistance in ovarian cancer. Clin. Cancer Res. 18, 869-881. doi: 10.1158/1078-0432.CCR-112188

Tang, Y., Gholamin, S., Schubert, S., Willardson, M. I., Lee, A., Bandopadhayay, P., et al. (2014). Epigenetic targeting of Hedgehog pathway transcriptional output through BET bromodomain inhibition. Nat. Med. 20, 732-740. doi: 10.1038/ nm.3613

Tang, Y. A., Chen, Y. F., Bao, Y., Mahara, S., Yatim, S. M. J. M., Oguz, G., et al. (2018). Hypoxic tumor microenvironment activates GLI2 via HIF-1 $\alpha$ and TGF$\beta 2$ to promote chemoresistance in colorectal cancer. Proc. Natl. Acad. Sci. U.S.A. 115, E5990-E5999. doi: 10.1073/pnas.1801348115

Teglund, S., and Toftgård, R. (2010). Hedgehog beyond medulloblastoma and basal cell carcinoma. Biochim. Biophys. Acta 1805, 181-208. doi: 10.1016/j.bbcan. 2010.01 .003

Teperino, R., Amann, S., Bayer, M., McGee, S. L., Loipetzberger, A., Connor, T., et al. (2012). Hedgehog partial agonism drives Warburg-like metabolism in muscle and brown fat. Cell 151, 414-426. doi: 10.1016/j.cell.2012.09.021

Tojo, M., Kiyosawa, H., Iwatsuki, K., Nakamura, K., and Kaneko, F. (2003). Expression of the GLI2 oncogene and its isoforms in human basal cell carcinoma. Br. J. Dermatol. 148, 892-897. doi: 10.1046/j.1365-2133.2003. 05284.x

Tsanev, R., Tiigimägi, P., Michelson, P., Metsis, M., Østerlund, T., and Kogerman, P. (2009). Identification of the gene transcription repressor domain of Gli3. FEBS Lett. 583, 224-228. doi: 10.1016/j.febslet.2008.12.010

Varjosalo, M., Björklund, M., Cheng, F., Syvänen, H., Kivioja, T., Kilpinen, S., et al. (2008). Application of active and kinase-deficient kinome collection for identification of kinases regulating hedgehog signaling. Cell 133, 537-548. doi: 10.1016/j.cell.2008.02.047

Varjosalo, M., and Taipale, J. (2008). Hedgehog: functions and mechanisms. Genes Dev. 22, 2454-2472. doi: 10.1101/gad.1693608

Wagner, A. J., Messersmith, W. A., Shaik, M. N., Li, S., Zheng, X., McLachlan, K. R., et al. (2015). A phase I study of PF-04449913, an oral hedgehog inhibitor, in patients with advanced solid tumors. Clin. Cancer Res. 21, 1044-1051. doi: 10.1158/1078-0432.CCR-14-1116

Wang, B., and Li, Y. (2006). Evidence for the direct involvement of \{beta\}TrCP in Gli3 protein processing. Proc. Natl. Acad. Sci. U.S.A. 103, 33-38. doi: 10.1073/ pnas.0509927103

Wang, Y., Ding, Q., Yen, C. J., Xia, W., Izzo, J. G., Lang, J. Y., et al. (2012). The crosstalk of mTOR/S6K1 and hedgehog pathways. Cancer Cell 21, 374-387. doi: 10.1016/j.ccr.2011.12.028

Wang, Y., Hsu, J. M., Kang, Y., Wei, Y., Lee, P. C., Chang, S. J., et al. (2016). Oncogenic functions of Gli1 in pancreatic adenocarcinoma are supported by its PRMT1-mediated methylation. Cancer Res. 76, 7049-7058. doi: 10.1158/00085472.CAN-16-0715

Wen, J., Lee, J., Malhotra, A., Nahta, R., Arnold, A. R., Buss, M. C., et al. (2016). WIP1 modulates responsiveness to Sonic Hedgehog signaling in neuronal precursor cells and medulloblastoma. Oncogene 35, 5552-5564. doi: 10.1038/ onc. 2016.96

Whisenant, T. C., Ho, D. T., Benz, R. W., Rogers, J. S., Kaake, R. M., Gordon, E. A., et al. (2010). Computational prediction and experimental verification of new MAP kinase docking sites and substrates including Gli transcription factors. PLoS Comput. Biol. 6:e1000908. doi: 10.1371/journal.pcbi.1000908

Whitson, R. J., Lee, A., Urman, N. M., Mirza, A., Yao, C. Y., Brown, A. S., et al. (2018). Noncanonical hedgehog pathway activation through SRF-MKL1 promotes drug resistance in basal cell carcinomas. Nat. Med. 24, 271-281. doi: $10.1038 / \mathrm{nm} .4476$

Winklmayr, M., Schmid, C., Laner-Plamberger, S., Kaser, A., Aberger, F., Eichberger, T., et al. (2010). Non-consensus GLI binding sites in Hedgehog target gene regulation. BMC Mol. Biol. 11:2. doi: 10.1186/1471-2199-11-2

Yamamoto, K., Tateishi, K., Kudo, Y., Hoshikawa, M., Tanaka, M., Nakatsuka, T., et al. (2016). Stromal remodeling by the BET bromodomain inhibitor JQ1 suppresses the progression of human pancreatic cancer. Oncotarget 7, 61469-61484. doi: 10.18632/oncotarget.11129

Yang, H., Hu, L., Liu, Z., Qin, Y., Li, R., Zhang, G., et al. (2017). Inhibition of Glil-mediated prostate cancer cell proliferation by inhibiting the mTOR/S6K1 signaling pathway. Oncol. Lett. 14, 7970-7976. doi: 10.3892/ol.2017.7254

Yang, Y., and Bedford, M. T. (2013). Protein arginine methyltransferases and cancer. Nat. Rev. Cancer 13, 37-50. doi: 10.1038/nrc3409

Yang, Z., Ma, H., Sun, Z., Luo, L., Tian, S., Zheng, J., et al. (2015). Discovery of a 6-(pyridin-3-yl)benzo[d]thiazole template for optimization of hedgehog and PI3K/AKT/mTOR dual inhibitors. Bioorg. Med. Chem. Lett. 25, 3665-3670. doi: 10.1016/j.bmcl.2015.06.049

Yedjou, C. G., and Tchounwou, P. B. (2007). In-vitro cytotoxic and genotoxic effects of arsenic trioxide on human leukemia (HL-60) cells using the MTT and alkaline single cell gel electrophoresis (Comet) assays. Mol. Cell Biochem. 301, 123-130. doi: 10.1007/s11010-006-9403-4

Yoon, J. W., Gallant, M., Lamm, M. L., Iannaccone, S., Vieux, K. F., Proytcheva, M., et al. (2013). Noncanonical regulation of the Hedgehog mediator GLI1 by c-MYC in Burkitt lymphoma. Mol. Cancer Res. 11, 604-615. doi: 10.1158/15417786.MCR-12-0441

Yoon, J. W., Lamm, M., Iannaccone, S., Higashiyama, N., Leong, K. F., Iannaccone, P., et al. (2015). p53 modulates the activity of the GLI1 oncogene through interactions with the shared coactivator TAF9. DNA Repair. 34, 9-17. doi: 10.1016/j.dnarep.2015.06.006

Yu, J. S., and Cui, W. (2016). Proliferation, survival and metabolism: the role of $\mathrm{PI} 3 \mathrm{~K} / \mathrm{AKT} / \mathrm{mTOR}$ signalling in pluripotency and cell fate determination. Development 143, 3050-3060. doi: 10.1242/dev.137075

Zhang, R., Huang, S. Y., Li, K. W., Li, Y. H., Hsu, W. H., Zhang, G. J., et al. (2017). Dual degradation signals destruct GLI1: AMPK inhibits GLI1 through $\beta$-TrCP-mediated proteasome degradation. Oncotarget 8, 49869-49881. doi: 10.18632/oncotarget.17769

Zhao, D., and Cui, Z. (2019). MicroRNA-361-3p regulates retinoblastoma cell proliferation and stemness by targeting hedgehog signaling. Exp. Ther. Med. 17, 1154-1162. doi: 10.3892/etm.2018.7062

Zhao, J., Quan, H., Xie, C., and Lou, L. (2014). NL-103, a novel dual-targeted inhibitor of histone deacetylases and hedgehog pathway, effectively overcomes vismodegib resistance conferred by Smo mutations. Pharmacol. Res. Perspect. 2:e00043. doi: 10.1002/prp2.43

Zhao, X., Ponomaryov, T., Ornell, K. J., Zhou, P., Dabral, S. K., Pak, E., et al. (2015). RAS/MAPK activation drives resistance to smo inhibition, metastasis, and tumor evolution in shh pathway-dependent tumors. Cancer Res. 75, 3623-3635. doi: 10.1158/0008-5472

Zhou, J., Zhu, G., Huang, J., Li, L., Du, Y., Gao, Y., et al. (2016). Non-canonical GLI1/2 activation by PI3K/AKT signaling in renal cell carcinoma: a novel potential therapeutic target. Cancer Lett. 370, 313-323. doi: 10.1016/j.canlet. 2015.11.006

Zhu, G., Zhou, J., Song, W., Wu, D., Dang, Q., Zhang, L., et al. (2013). Role of GLI1 in epidermal growth factor-induced invasiveness of ARCaPE prostate cancer cells. Oncol. Rep. 30, 904-910. doi: 10.3892/or.2013.2534

Zwerner, J. P., Joo, J., Warner, K. L., Christensen, L., Hu-Lieskovan, S., Triche, T. J., et al. (2008). The EWS/FLI1 oncogenic transcription factor deregulates GLI1. Oncogene 27, 3282-3291. doi: 10.1038/sj.onc.1210991

Conflict of Interest Statement: The authors declare that the research was conducted in the absence of any commercial or financial relationships that could be construed as a potential conflict of interest.

Copyright (C) 2019 Pietrobono, Gagliardi and Stecca. This is an open-access article distributed under the terms of the Creative Commons Attribution License (CC BY). The use, distribution or reproduction in other forums is permitted, provided the original author(s) and the copyright owner(s) are credited and that the original publication in this journal is cited, in accordance with accepted academic practice. No use, distribution or reproduction is permitted which does not comply with these terms. 